\title{
MASTER \\ GEOTHERMAL RESERVOIR ENGINEERING COMPUTER CODE COMPARISON \\ AND VALIDATION USING THE GEONZ SIMULATOR PROGRAM
}

\author{
by \\ Roland N. Horne \\ David 0. Ogbe \\ Kwaku Temeng \\ Henry J. Ramey, Jr.
}

i.

\begin{abstract}
Final Report to the Department of Energy November 14,1980
\end{abstract}

Contract DE-AC03-80SF11450

Principal Investigator: Henry J. Ramey, Jr. 


\section{DISCLAIMER}

This report was prepared as an account of work sponsored by an agency of the United States Government. Neither the United States Government nor any agency Thereof, nor any of their employees, makes any warranty, express or implied, or assumes any legal liability or responsibility for the accuracy, completeness, or usefulness of any information, apparatus, product, or process disclosed, or represents that its use would not infringe privately owned rights. Reference herein to any specific commercial product, process, or service by trade name, trademark, manufacturer, or otherwise does not necessarily constitute or imply its endorsement, recommendation, or favoring by the United States Government or any agency thereof. The views and opinions of authors expressed herein do not necessarily state or reflect those of the United States Government or any agency thereof. 


\section{DISCLAIMER}

Portions of this document may be illegible in electronic image products. Images are produced from the best available original document. 
TABLE OF CONTENTS

$\begin{array}{ll}1.0 \text { INTRODUCTION AND SUMMARY } & 1\end{array}$

2.0 SELECTION OF THE GEONZ COMPUTER CODE 2

3.0 RESULTS

3.1 Problem No. 1: 1-D Avdonin Solution 5

3.2 Problem No. 2: 1-D Well Test Analysis 13

3.3 Problem No. 3: 2-D Flow In Fracture/Block Medium 14

3.4 Problem No. 4: 2-Phase System with Drainage 25

3.5 Problem No. 5: Flow in 2-D Areal Reservoir 32

REFERENCES

APPENDIX $\quad 54$

Problem Specifications $\quad 54$ 


\subsection{INTRODUCTION AND SUMMARY}

The Stanford approach to the geothermal simulator code comparison project was that of a user working with a program authored by another group. It was originally proposed to use the Zyvoloski and O'Sullivan GEOTHERM geothermal simulator program to prepare solutions to the first. five of the six Department of Energy computer code comparison sets. Valid solutions were anticipated in all of the five problems attempted, but it was expected that problems 3 and 4 might present some difficulties--problem 3 because it might produce superheated conditions beyond the range of the program's thermodynamics subroutines, and problem 4 because it might produce counterflows of steam and water which would be problematical in view of the program's method of assigning an "upstream" node.

In fact, a more recent version of the program, called GEONZ (by Zyvoloski, :Blakely, and 0'Sullivan), became available to us during the contract period, and was used successfully on problems 3 and 4. The new program, GEONZ, had additional capabilities that enabled it to handle both superheated steam and counterflows of steam and water.

Some delays had been anticlpated in the installation of the program, and in familiarization of the contractors with its use. In the actual event, installation was accomplished in a very short period of time, but familiarization took somewhat longer. There was some additional delay with the arrival of the updated program GEONZ; however, the familiarization difficulties were finally overcome elther by in-depth examination of the source code or, In many cases, consultation with its authors. 
In general, the GEONZ should be classifled as a laboratory code, although It lacks only a very few conveniences to align it with commercial simulators. The necessity of entering the code to program each of the problems was a time-consuming task, and the major source of errors during the contract. There were also some additional pitfalls of data entry that could be avoided with some data checking by the program or possibly by some more extensive output stating more clearly the implications of some of the "flags" which had been set or unset. In spite of these vagaries, the GEONZ code was impressively rapid in its operation, and the high efficiency of its computation algorlthms reduced the actual computer costs to one-third of those budgeted. Unfortunately, this saving in cost was absorbed by the additional human labor costs necessary to overcome the programming difficulties within the contract period. In brief, it cost us very much more in human cost than in computer cost to solve the problem set. With commercialization of the program, we anticipate that the two costs would become about equal.

In the following sections, the cholce of the GEONZ code is discussed, followed by an in-depth description of the solutions obtained for problems 1 through 5. The problem statements are included as Appendix A of this report.

\subsection{SELECTION OF. THE GEONZ COMPUTER CODE}

As a program user, the criterla for selection of a computer code were necessarily different from those of a program author making a choice between codes of his own authorship. The primary criterla were the same--that the program should be capable of performing the required tasks accurately and efficiently. However, equally important to the user, he must be able to 
make the program perform those tasks. The program therefore had to be readily installed, well documented, and well supported.

Considering first the primary criteria of accuracy, applicability, and efficiency, it was determined that the major source of inaccuracy in geothermal reservoir simulators arose during calculations involving a change of phase. The difficulty here is that some properties of the reservoir fluid (for example, compressibility, density, viscosity) go through orderof-magnitude changes from one phase to the other. Since the basis of numerical methods is usually to consider finite changes in a difference approximation to the rate of change of these properties, the discontinuity of derivatives at the phase boundary is the major source of difficulty. Much of this difficulty may be overcome in the careful selection of the dependent variables. In the absence of noncondensable gases, the dependent varlables may usually be reduced to two.

The two dependent variables used in the GEONZ program based on the work described by Zyvoloski, O'Sullivan, and Krol (1979), are mixture enthalpy and pressure. The advantage of the choice of these two dependent varlables Is that neither of them undergoes order-of-magnitude changes in gradient through phase changes. The pressure is in fact constant throughout a phase change. This cholce of dependent variables was therefore considered to have advantages over alternatives used by other codes; for example, density and internal energy used in the $\mathrm{s}^{3}$ model (Pritchett, Garg, Brownell, and Levine, 1975), and also in LBL's SHAFT (Pruess, 1978). The reservoir simulator of Faust and Mercer (1979) also uses the desirable combination of pressure and enthalpy, and could therefore be considered a candidate program, along with GEONZ; on the basis of expected success in two-phase calculations. Moving on to consideration of efficiency, it was determined that 
the GEONZ code is computationally more streamlined than the Faust-Mercer program. Both use the Newton-Raphson method (see Zyvoloski, O'Sullivan, and Krol, 1.979) to solve Implicit nonlinear finite difference approximations to the governing equations. However, the computational procedures used in GEONZ are more compact since they Involve the solution of small and sparse matrix equations. The use of the ADI method in GEONZ reduces the number of iterations in any particular area to that necessary to achieve local accuracy of the solution. The procedure used by Faust and Mercer (1979) requires global iteration. This is particular1y important since typically local convergence is extremely fast except at a few points in the vicinity of a phase change. Since a substantial portion of the computation time is involved in function evaluation, the added computational overhead of the ADI scheme in reducing the number of function evaluations is extremely worthwhile. The GEONZ program was therefore found to be most acceptable under the primary criteria.

The secondary criteria of availability and ease of installation, use, and support highlighted two programs: GEONZ and SHAFT. Both were already Implemented on facilities geographically close to the investigators, as were their support teams. Both had the added advantage that authors of the programs were readily accessible to the investigators. SHAFT has a greater degree of user orfentation and support. On the other hand, one of the investigators in this project had a greater familiarity with GEONZ; having been associated with the research effort under which it was written (although not involved in the program 1tself).

A final consideration in the selection of GEONZ was specific to DOE's objective of ascertaining the validity of geothermal reservoir simulators. Although preferable under our technicál criteria, GEONZ was probably not 
as we1l known to the U.S. geothermal community, having been written overseas. It was funded by the New Zealand government under a contract through the New Zealand Energy Research and Development Committee, and is public property. Although newer on the scene and not as user orfented as some other codes, the more recent preparation of GEONZ permitted the avoidance of many of the disadvantages of codes produced somewhat earlier. The innovative and compact GEONZ program should certainly have contributed significant1y to the demonstration of geothermal reservoir simulators.

\subsection{RESULTS}

The results of problems 1 through 5 of the Department of Energy geothermal simulator computer code comparison are given in Sections 3.1 through 3.5. respectively. Tables and diagrams are prefixed by problem number.

\subsection{Problem No. 1: 1-D Avdonin Solution}

This problem was solved using the mesh specified in the problem statement (see Appendix A). The time step size used was $4.175 \times 10^{6}$ secs, one quarter of that suggested. This size time step was necessary to achieve numericăl stability.

The temperature versus radial distance at $10^{9} \mathrm{sec}$ is shown in Table 1.1 and in Fig. 1.1, and the temperature at radius 37.5 meters as a function of time is shown in Table 1.2 and in Fig. 1.2.

The properties of water at $165^{\circ} \mathrm{C}$ and 50 bars calculated by the program thermodynamics package are as follows:

$$
\begin{aligned}
\text { specific heat } & =4.45 \mathrm{KJ} / \mathrm{kg}^{\circ} \mathrm{C} \\
\text { kinetic viscosity } & =1.6362 \times 10^{-4} \mathrm{~N} . \mathrm{s} / \mathrm{m}^{2} \\
\text { density } & =906.596 \mathrm{~kg} / \mathrm{m}^{3}
\end{aligned}
$$


- $-6-$

TABLE 1.1: PROBLEM 1, TEMPERATURE AT $10^{9}$ SEC

\begin{tabular}{|r|c|}
\hline Radius (m) & $T\left({ }^{\circ} \mathrm{C}\right)$ \\
\hline 12.5 & 160.271 \\
37.5 & 159.802 \\
62.5 & 160.163 \\
87.5 & 160.506 \\
112.5 & 160.728 \\
137.5 & 162.267 \\
162.5 & 162.618 \\
187.5 & 164.786 \\
212.5 & 165.279 \\
237.5 & 167.196 \\
262.5 & 167.669 \\
287.5 & 168.900 \\
312.5 & 169.236 \\
337.5 & 169.847 \\
362.5 & 170.035 \\
387.5 & 170.278 \\
412.5 & 170.363 \\
437.5 & 170.441 \\
462.5 & 170.474 \\
487.5 & 170.494 \\
512.5 & 170.505 \\
537.5 & 170.509 \\
562.5 & 170.512 \\
587.5 & 170.512 \\
612.5 & 170.513 \\
637.5 & 170.513 \\
662.5 & 170.514 \\
687.5 & 170.513 \\
712.5 & 170.514 \\
737.5 & 170.514 \\
762.5 & 170.514 \\
787.5 & 170.513 \\
812.5 & 170.513 \\
837.5 & 170.513 \\
862.5 & 170.513 \\
887.5 & 170.513 \\
912.5 & 170.513 \\
937.5 & 170.513 \\
962.5 & 170.513 \\
987.5 & 170.513 \\
& \\
\hline & \\
\hline & \\
\hline
\end{tabular}




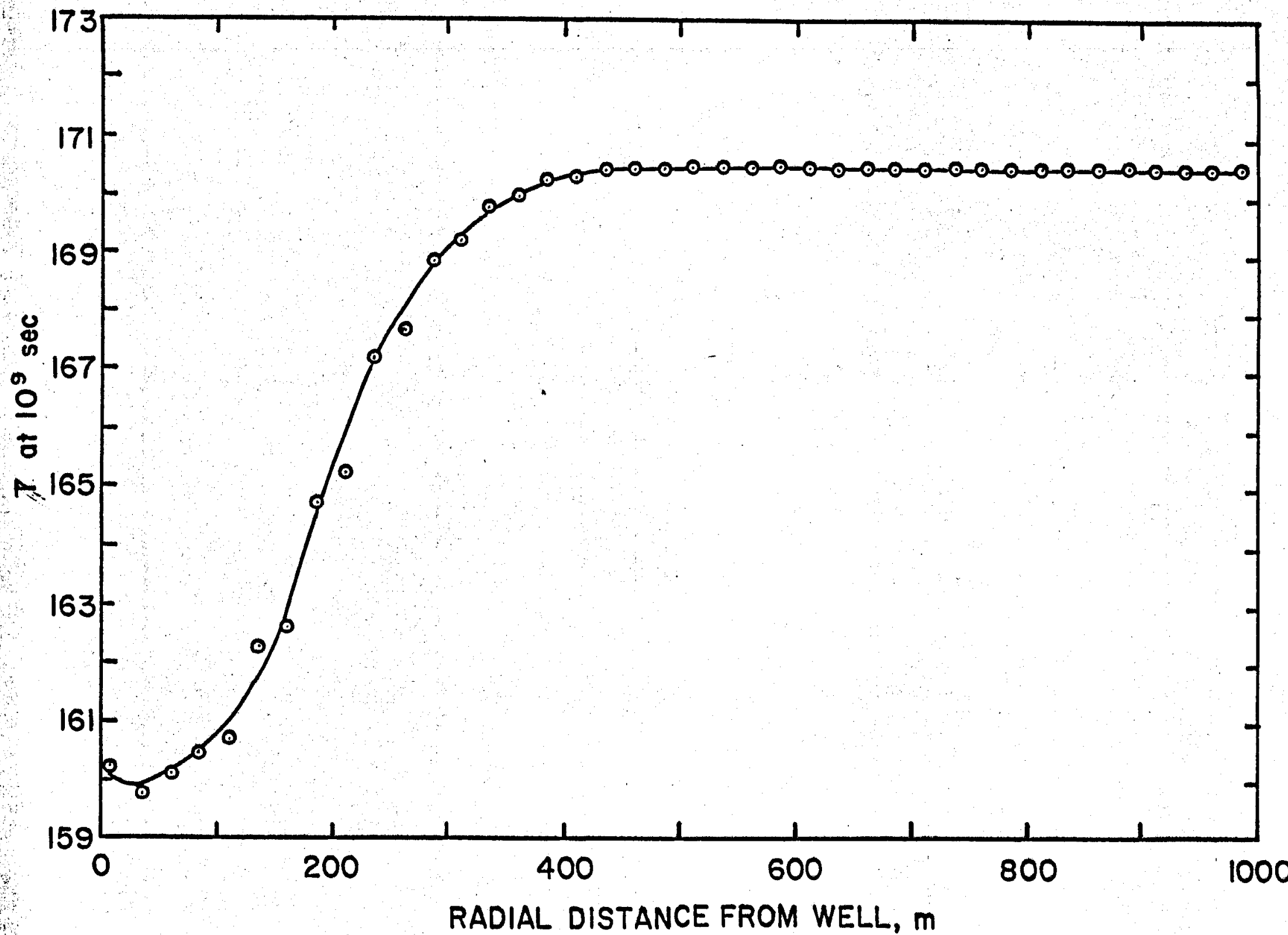

FIG. 1.1: PROBLEM 1 


$$
-8-
$$

TABLE 1.2: PROBLEM 1, TEMPERATURE AT $37.5 \mathrm{~m}$ AS A FUNCTION OF TIME

\begin{tabular}{|l|l|}
\hline Time (Secs) & $\begin{array}{c}\text { Temperature } \\
\text { at } 37.5 \mathrm{~m}\end{array}$ \\
\hline $.835\left(10^{7}\right)$ & 169.746 \\
$.2505\left(10^{8}\right)$ & 167.482 \\
$.4175\left(10^{8}\right)$ & 165.346 \\
$.5845\left(10^{8}\right)$ & 163.672 \\
$.7515\left(10^{8}\right)$ & 162.439 \\
$.9185\left(10^{8}\right)$ & 161.614 \\
$.1753\left(10^{9}\right)$ & 160.262 \\
$.2588\left(10^{9}\right)$ & 160.123 \\
$.3340\left(10^{9}\right)$ & 160.224 \\
$.4258\left(10^{9}\right)$ & 160.094 \\
$.5093\left(10^{9}\right)$ & 160.012 \\
$.5928\left(10^{9}\right)$ & 159.642 \\
$.6763\left(10^{9}\right)$ & 159.820 \\
$.7598\left(10^{9}\right)$ & 159.962 \\
$.8433\left(10^{9}\right)$ & 160.030 \\
$.9268\left(10^{9}\right)$ & 160.192 \\
$.9435\left(10^{9}\right)$ & 160.076 \\
$.9602\left(10^{9}\right)$ & 160.019 \\
$.9769\left(10^{9}\right)$ & 159.978 \\
$.9936\left(10^{9}\right)$ & 159.916 \\
& \\
\hline & \\
\hline .93
\end{tabular}


C

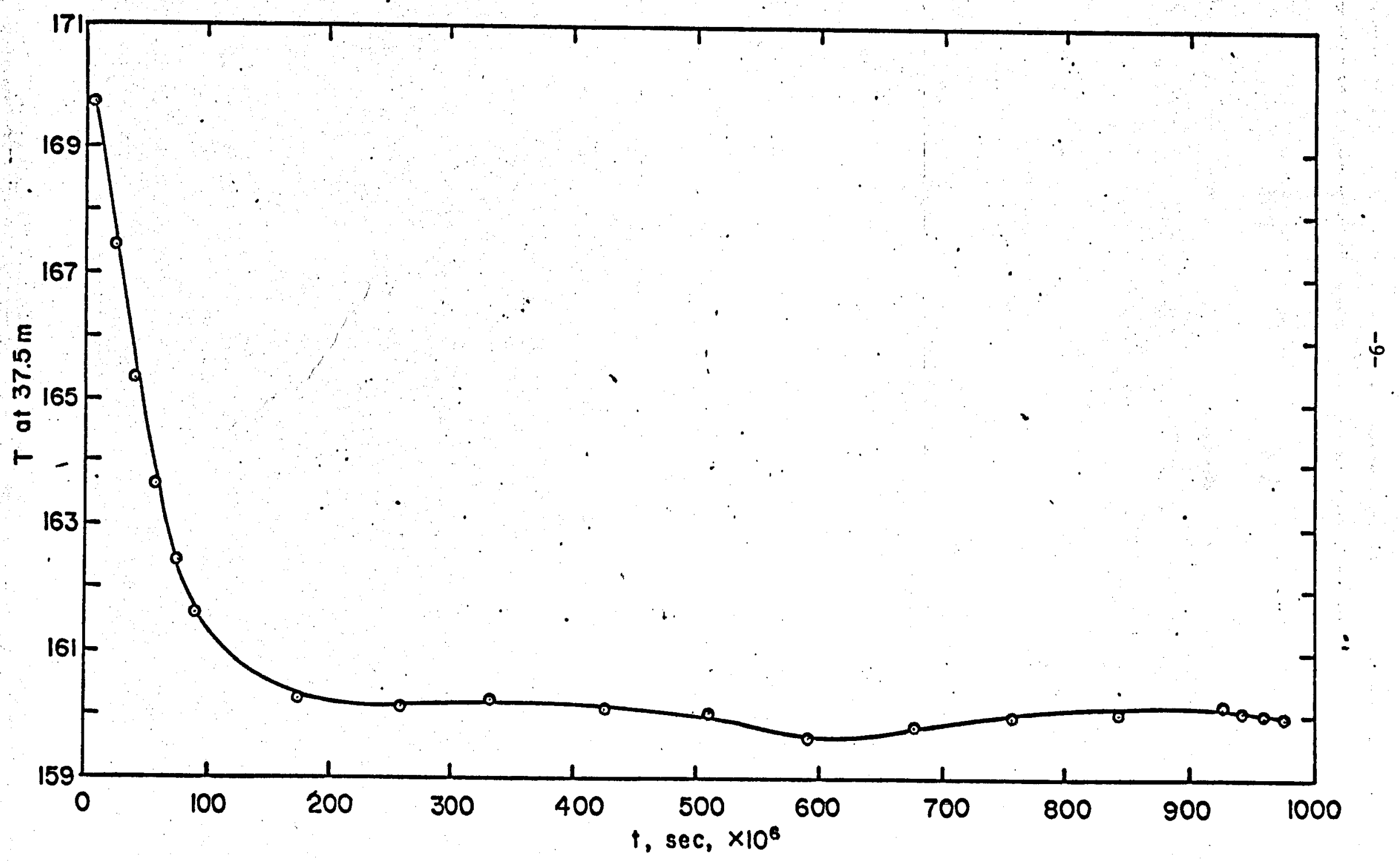

FIG. 1.2: PROBLEM 1 
TABLE 2.1: PROBLEM 2(a)

\begin{tabular}{|c|c|c|c|c|c|c|}
\hline \multirow{2}{*}{$t / r^{2}\left(\right.$ Day $\left./ \mathrm{m}^{2}\right)$} & \multicolumn{2}{|c|}{$x=0.5 \mathrm{~m}$} & \multicolumn{2}{|c|}{$x=0.707 \mathrm{~m}$} & \multicolumn{2}{|c|}{$r=1.0 \mathrm{~m}$} \\
\hline & $\begin{array}{c}\text { Press, P } \\
\text { (MPa) }\end{array}$ & $\begin{array}{c}\text { Flowing } \\
\text { Enthalpy } \\
\text { h, (MJ/kg) }\end{array}$ & $\begin{array}{c}\text { Pressure } \\
(\mathrm{MPa})\end{array}$ & $\begin{array}{l}\text { Flowling: } \\
\text { Enthalpy } \\
(\mathrm{MJ} / \mathrm{kg})\end{array}$ & $\begin{array}{l}\text { Pressure } \\
\text { (MPa) }\end{array}$ & $\begin{array}{l}\text { Flowing } \\
\text { Enthalpy } \\
(\mathrm{MJ} / \mathrm{kg})\end{array}$ \\
\hline 0.00001 & - & - & - & - & 8.9271 & 1.1338 \\
\hline 0.00002 & - & - & 8.8416 & 1.1337 & 8.8411 & 1.1337 \\
\hline 0.00004 & 8.7142 & 1.1336 & 8.7542 & 1.1336 & 8.7675 & 1.1336 \\
\hline 0.00008 & 8.6860 & 1.1335 & 8.6700 & 1.1335 & 8.6800 & 1.1335 \\
\hline 0.00010 & 8.6072 & 1.1335 & 8.6524 & 1.1335 & 8.6499 & 1.1335 \\
\hline 0.0002 & 8. 5442 & 1.1334 & 8.5496 & 1.1334 & 8.5488 & 1.1334 \\
\hline 0.0004 & 8.4533 & 1.1333 & 8.4513 & 1.1333 & 8.4523 & 1.1333 \\
\hline 0.0008 & 8.3474 & 1.1332 & 9.3540 & 1.1332 & 8.3528 & 1.1332 \\
\hline 0.0012 & 8.2936 & 1.1332 & 8.2956 & 1.1332 & 8.2939 & 1.1332 \\
\hline 0.002 & 8.2200 & 1.1331 & 8.2213 & 1.1331 & 8.2195 & 1.1331 \\
\hline 0.004 & 8.1171 & 1.1330 & 8.1199 & 1.1330 & 8.1183 & 1.1330 \\
\hline 0.008 & 8.0161 & 1.1329 & 8.0180 & 1.1329 & 8.0170 & 1.1329 \\
\hline 0.01 & 7.9850 & 1.1329 & 7.0952 & 1.1329 & 7.9843 & 1.1329 , \\
\hline 0.02 & 7.8823 & 1.1328 & 7.8831 & 1.1328 & 7.8822 & 1.1328 \\
\hline 0.04 & 7.7810 & 1.1327 & 7.7802 & 1.1328 & 7.7809 & 1.1328 \\
\hline 0.08 & 7.6790 & 1.1327 & 7.6789 & 1.1327 & 7.6795 & 1.1327 \\
\hline 0.1 & 7.6461 & 1.1326 & 7.6463 & 1.1327 & 7.6468 & 1.1327 \\
\hline 0.2 & 7.5451 & 1.1326 & 7.5448 & 1.1327 & 7.5451 & 1.1326 \\
\hline 0.4 & 7.4435 & 1.1325 & 7.4437 & 1.1327 & 7.4434 & 1.1326 \\
\hline 0.8 & 7.3416 & 1.1326 & 7.3421 & 1.1326 & 7.3414 & 1.1326 \\
\hline 1.0 & 7.3092 & 1.1326 & 7.3093 & 1.1326 & 7.3091 & 1.1326 \\
\hline 1.2 & 7.2822 & 1.1326 & 7.2826 & 1.1326 & - & - \\
\hline 2.0 & 7.2073 & 1.1325 & 7.2077 & 1.1326 & - & 一 \\
\hline 4.0. & 7.1056 & 1.1326 & - & - & - & 一 \\
\hline
\end{tabular}




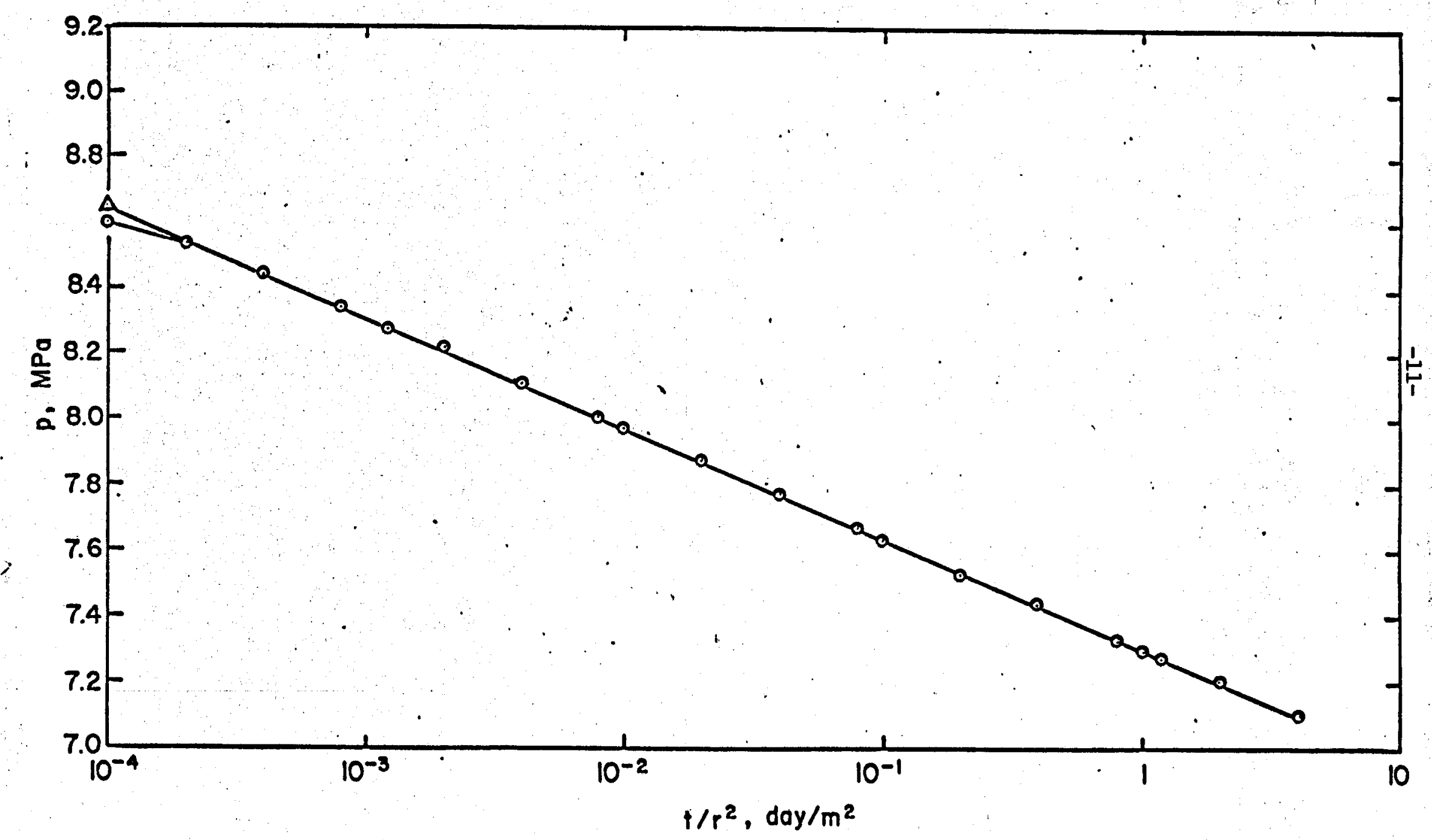

FIG. 2.1: PROBLEM 2(a) 

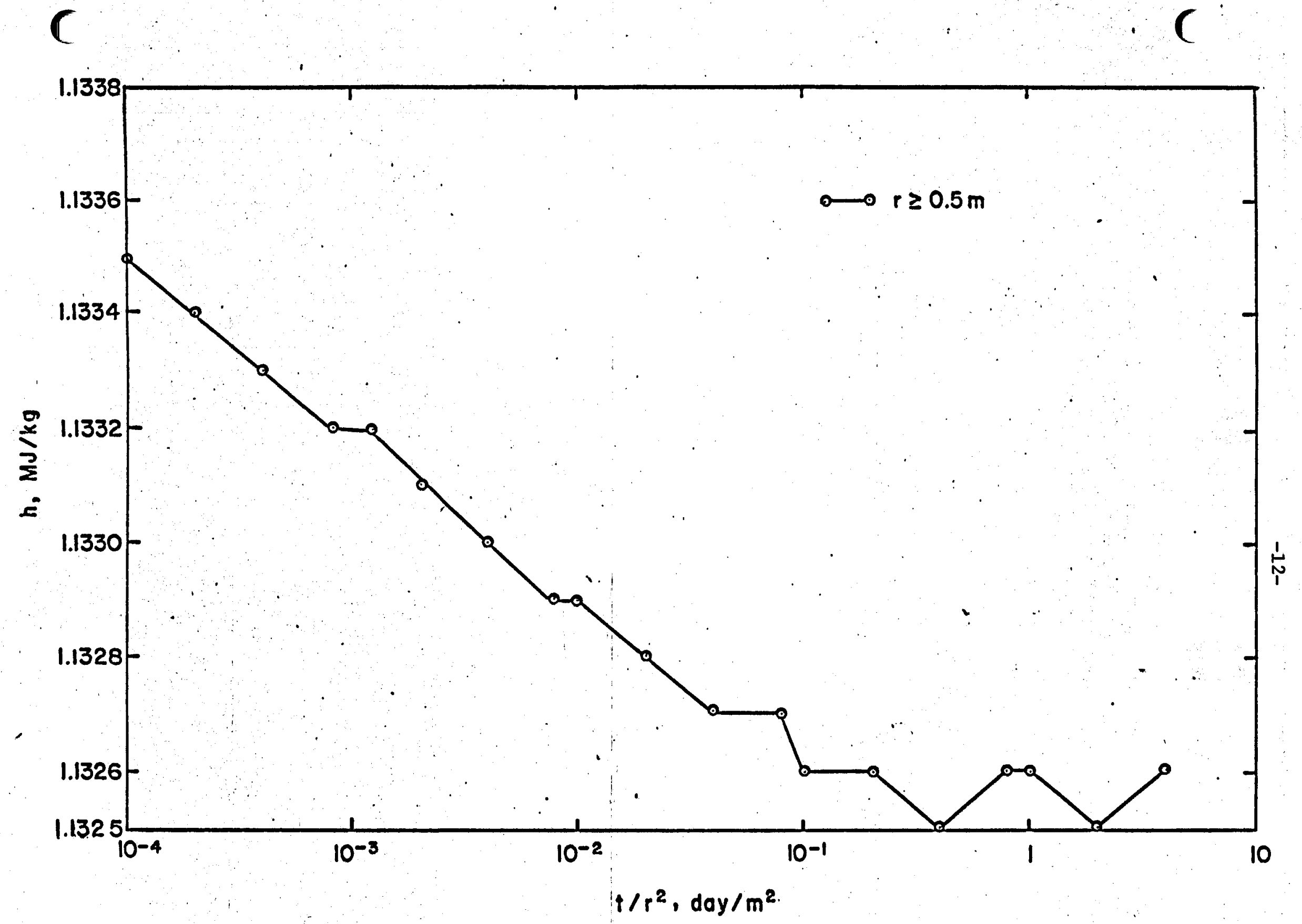

FIG. 2.2: PROBLEM 2(a) 


\subsection{Problem No. 2: 1-D Well Test Analysis}

This problem proved to be the most time consuming of the five, due to the necessity of experimentation with time step size for each of the three problems. All output in this problem was graphed semilog for quick evaluation of Theis-type behavior.

The outer boundary condition (not specified in the problem statement) was taken to be at constant pressure and enthalpy equal to the inftial pressure and enthalpy.

\section{Case (a)}

The time step sequence used was 10 steps of $10^{-5}$ days, fóllowed by 100 each of $10^{-4}$ and $10^{-3}$ days with the remainder (up to 1 day) at $10^{-2}$ days.

The pressure and enthalpy as a function of $t / r^{2}$ (time/radius squared) are tabulated in Table 2.1 and graphed in Figs. 2.1- and 2.2. The pressures at radil $0.5,0.707$, and 1.0 meters radius (graphed in Fig. 2.1 as a function of $t / r^{2}$ ) are so close to each other as to be indistinguishable on the graph except at very early time. The graph shows the correct Theis semilog straight line behavior.

\section{Case (b)}

The two-phase mixture case proved to be the most difficult in terms of time step selection, and required more time steps than did cases a and c. The sequence was 10 steps of $10^{-5}$ days, followed by 20 steps each of $2 \times 10^{-5}$ and $5 \times 10^{-5}$, followed by 10 of $10^{-4}$ days, 10 of $2.5 \times 10^{-4}$ days, 30 of $5 \times 10^{-4}$ days, 180 of $10^{-3}$ days, 100 of $1.25 \times 10^{-3}$ days, and the remainder (up to 1 day) at $1.5 \times 10^{-3}$ days. The largest time step was thus $1.5 \times 10^{-3}$ days, compared to 0.01 days in Case $a$ and $2 \times 10^{-3}$ days in Case $c$. 
The pressure, saturation, and flowing enthalpy at radi1 $0.5,0.707$, and 1.0 meters as a function of $t / \mathrm{r}^{2}$ are shown in Table 2.2 and in Figs. 2.3, 2.4, and 2.5. There is good agreement between these results and those of Sorey, Grant, and Bradford (1980) for the same problem (see their Fig. 1).

Case (c)

The sequence of time steps taken was 10 steps at $10^{-5}$ days, 20 each of $2 \times 10^{-5}$ and $5 \times 10^{-5}$ days, 10 each of $10^{-4}$ and $2.5 \times 10^{-4}$ days, 30 of $5 \times 10^{-4}$ days, $: 180$ of $10^{-3}$, and the remainder (up to 1 day) of $2 \times 10^{-3}$ days. The pressure, saturation, and flowing enthalpy as a function of $t / r^{2}$ are tabulated in Table 2.3 and graphed in Figs. 2.6, 2.7, and 2.8.

\section{Case (d): One-Node Problem}

This solution was achieved using a single cylindrical grid block of radius $10 \mathrm{~m}$ and thickness $1 \mathrm{~m}$. The pressure, saturation, and flowing enthalpy are tabulated in Table 2.4 and graphed in Fig. 2.9.

\subsection{Problem No. 3: 2-D Flow in Fracture/Block Medium}

This problem was solved using the nodal positions (block-centered) as specified in the problem statement. Setting up of the problem was somewhat complicated by the fact that the well radius $1 \mathrm{~s} 0.16 \mathrm{~m}$, which puts the well block boundary at the position calculated for the well block node using the geometric progression of block-centered node positions. This difficulty was overcome by overriding the coordinates calculated by the program, so that the well block node lay at $0.159 \mathrm{~m}$ radius and the well block boundary lay at $0.16 \mathrm{~m}$. The second and later nodes lay at $0.4 \mathrm{~m}$, $1.0 \mathrm{~m}$, etc., in the normal manner. The single well block exterior to the main grid also required some circuitry in the source code which works on 
TABLE 2.2: PROBLEM 2(b)

\begin{tabular}{|c|c|c|c|c|c|c|c|c|c|}
\hline \multirow{2}{*}{$t / r^{2}\left(D a y / m^{2}\right)$} & \multicolumn{3}{|c|}{$r=0.5 \mathrm{~m}$} & \multicolumn{3}{|c|}{$i x=0.707 \mathrm{~m}$} & \multicolumn{3}{|c|}{$=-1.0 \mathrm{~m}$} \\
\hline & $P,(M P a)$ & Saturation & $h\left(\mathrm{MJ} / \mathrm{Kg}_{\mathrm{g}}\right)$ & $\mathbf{P}$ & Saturation & h & $\mathbf{P}$ & Saturation & $\mathbf{h}$ \\
\hline 0.00001 & - & - & - & - & - & - & 3.0000 & 0.6500 & 1.3332 \\
\hline 0.00002 & - & - & - & 3.00000 & 0.6500 & 1.3332 & 3.0000 & 0.6500 & 1.3332 \\
\hline 0.00004 & 2.9988 & 0.6489 & 1.3333 & 2.9999 & 0.6499 & 1.3332 & 3.0000 & 0.6500 & 1.3332 \\
\hline 0.00008 & 2.9977 & 0.6478 & 1.3334 & 2.9998 & 0.6498 & 1.3332 & 3.0000 & 0.6499 & 1.3332 \\
\hline 0.00012 & 2.9965 & 0.6468 & 1.3337 & 2.9996 & 0.6496 & 1.3332 & 2.9999 & 0.6499 & 1.3332 \\
\hline 0.0002 & 2.9942 & 0.6448 & 1.3347 & 2.9989 & 0.6489 & 1.3334 & 2.9997 & 0.6497 & 1.3332 \\
\hline 0.0004 & 2.9886 & 0.6402 & 1.3387 & 2.9961 & 0.6464 & 1.3346 & 2.9983 & 0.6486 & 1.3337 \\
\hline 0.0008 & 2.9776 & 0.6323 & 1.3522 & 2.9875 & 0.6395 & 1.3415 & 2.9915 & 0.6426 & 1.3379 \\
\hline 0.0012 & 2.9669 & 0.6258 & 1.3708 & 2.9766 & 0.6322 & 1.3549 & 2.9805 & 0.6346 & 1.3489 \\
\hline 0.002 & 2.9464 & 0.6158 & 1.4151 & 2.9526 & 0.6205 & 1.3972 & 2.9533 & 0.6205 & 1.3914 \\
\hline 0.004 & 2.9003 & 0.6005 & 1.5175 & 2.8974 & 0.6055 & 1.5180 & 2.8930 & 0.6045 & 1.5238 \\
\hline 0.008 & 2.8294 & 0.5876 & 1.6293 & 2.8223 & 0.5946 & 1.6374 & 2.8208 & 0.5949 & 1.6382 \\
\hline 0.01 & 2.8028 & 0.5852 & 1.6616 & 2.7971 & 0.5924 & 1.6668 & $2: 7968$ & 0.5928 & 1.6657 \\
\hline 0.02 & 2.7186 & 0.5826 & 1.7287 & 2.7189 & 0.5876 & 1.7252 & 2.7195 & 0.5878 & 1.7241 \\
\hline 0.04 & 2.6377 & 0.5820 & 1.7593 & 2.7385 & 0.5843 & 1.7581 & 2.6387 & 0.5843 & 1.7582 \\
\hline 0.08 & 2.5549 & 0.5806 & 1.7768 & 2.5551 & 0.5817 & 1.7769 & 2.5552 & 0.5816 & 1.7770 \\
\hline 0.1 & 2.5279 & 0.5800 & 1.7810 & 2.5280 & 0.5809 & 1.7812 & 2.5280 & 0.5809 & 1.7813 \\
\hline 0.2 & 2.4413 & 0.5783 & 1.7893 & 2.4413 & 0.5787 & 1.7894 & 2.4413 & 0.5787 & 1.7894 \\
\hline 0.4 & 2.3522 & 0.5765 & 1.7937 & 2.3522 & 0.5767 & 1.7937 & 2.3522 & 0.5767 & 1.7938 \\
\hline 0.8 & 2.2606 & 0.5746 & 1.7960 & 2.2606 & 0.5747 & 1.7960 & 2.2605 & 0.5747 & 1.7960 \\
\hline 1.0 & 2.2300 & 0.5738 & 1.7978 & 2.2299 & 0.5739 & 1.7978 & 2.2300 & 0.5739 & 1.7978 \\
\hline 1.2 & 2.2053 & 0.5734 & 1.7971 & 2.2054 & 0.5735 & 1.7971 & - & 一 & - \\
\hline 2.0 & 2.1346 & 0.5718 & 1.7988 & 2.1347 & 0.5718 & 1.7988 & - & - & 一 \\
\hline 4.0 & 2.0364 & 0.5696 & 1.7994 & - & - & - & - & 一 & - \\
\hline
\end{tabular}




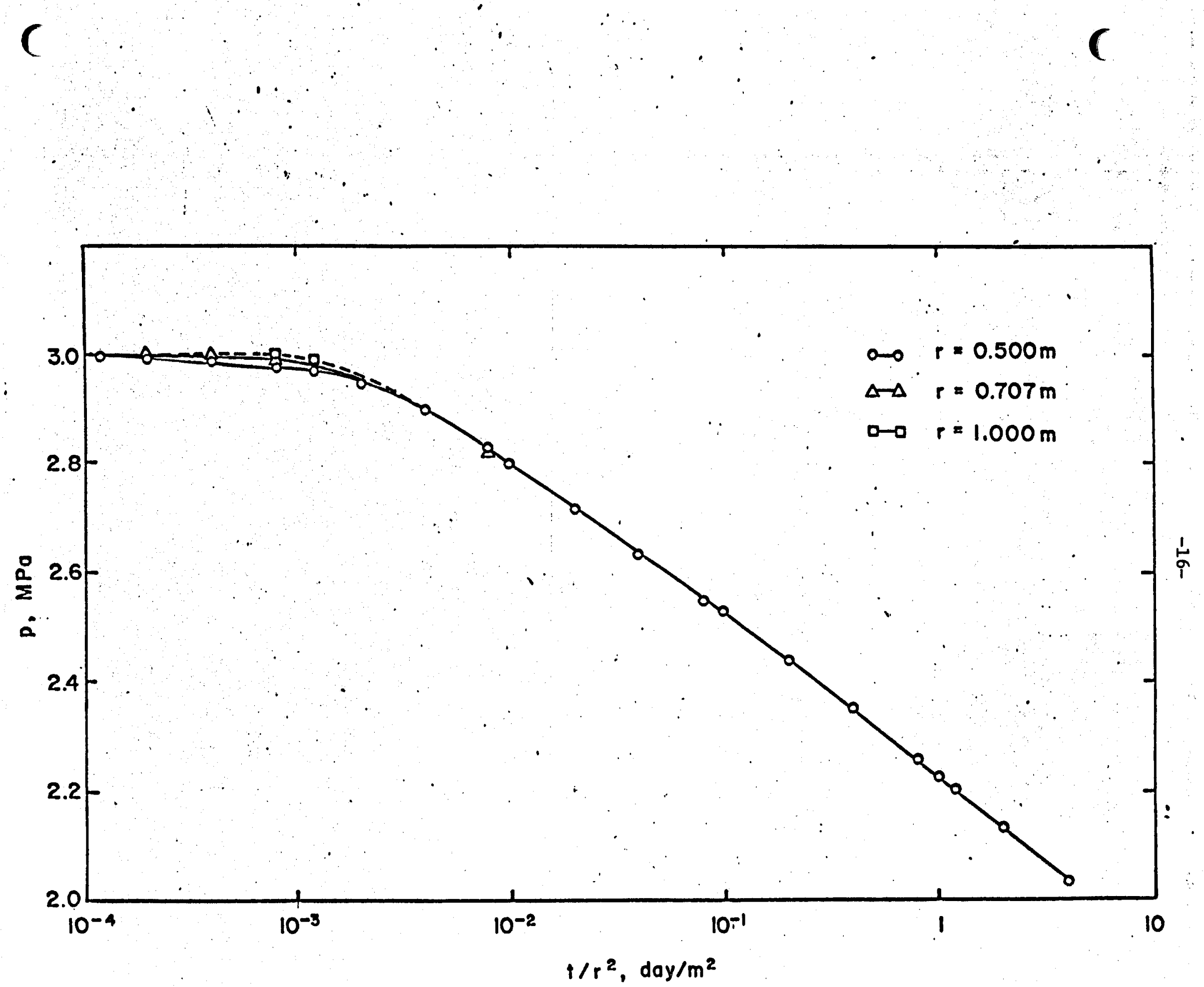

FIG. 2.3: PROBLEM 2(b) 


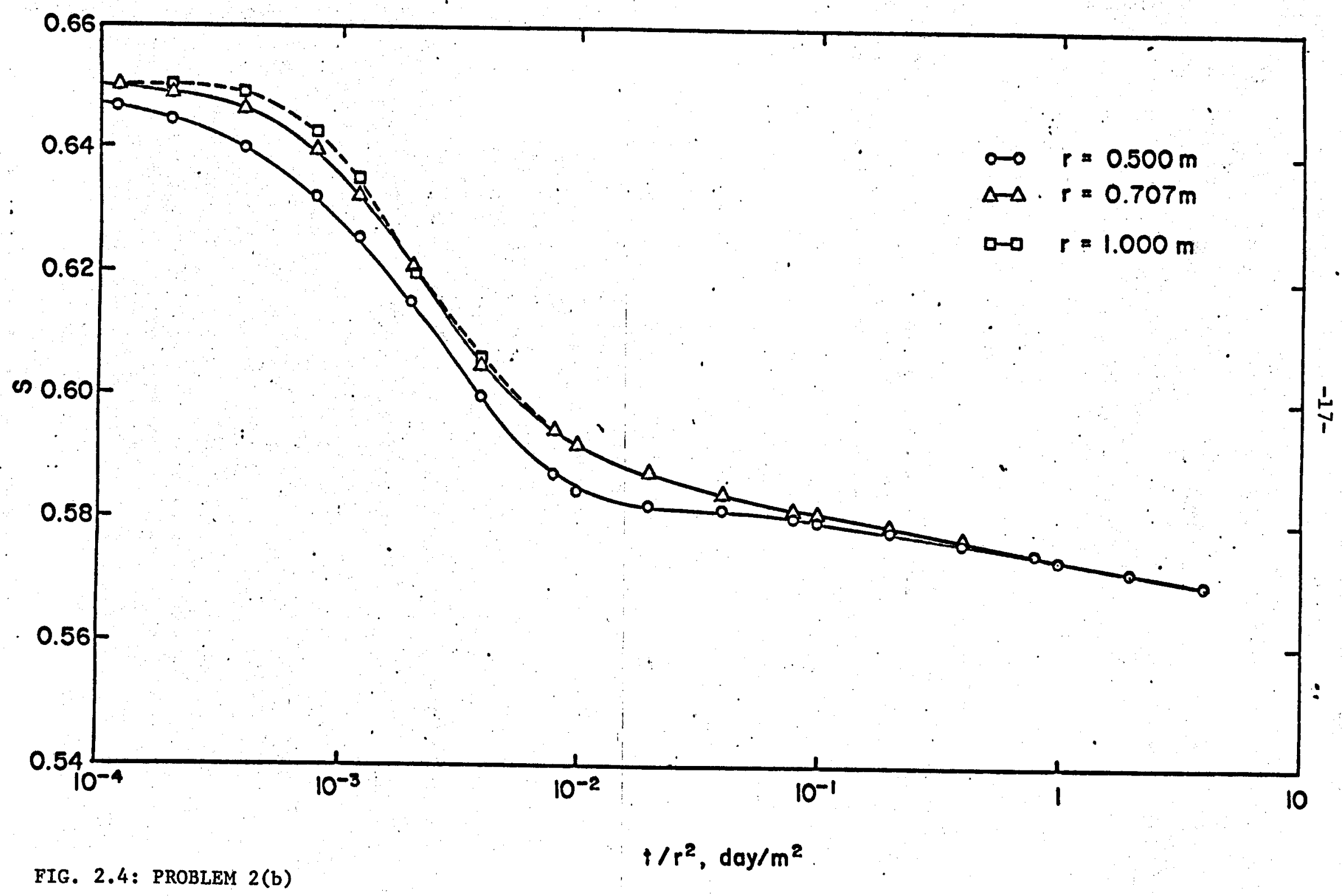




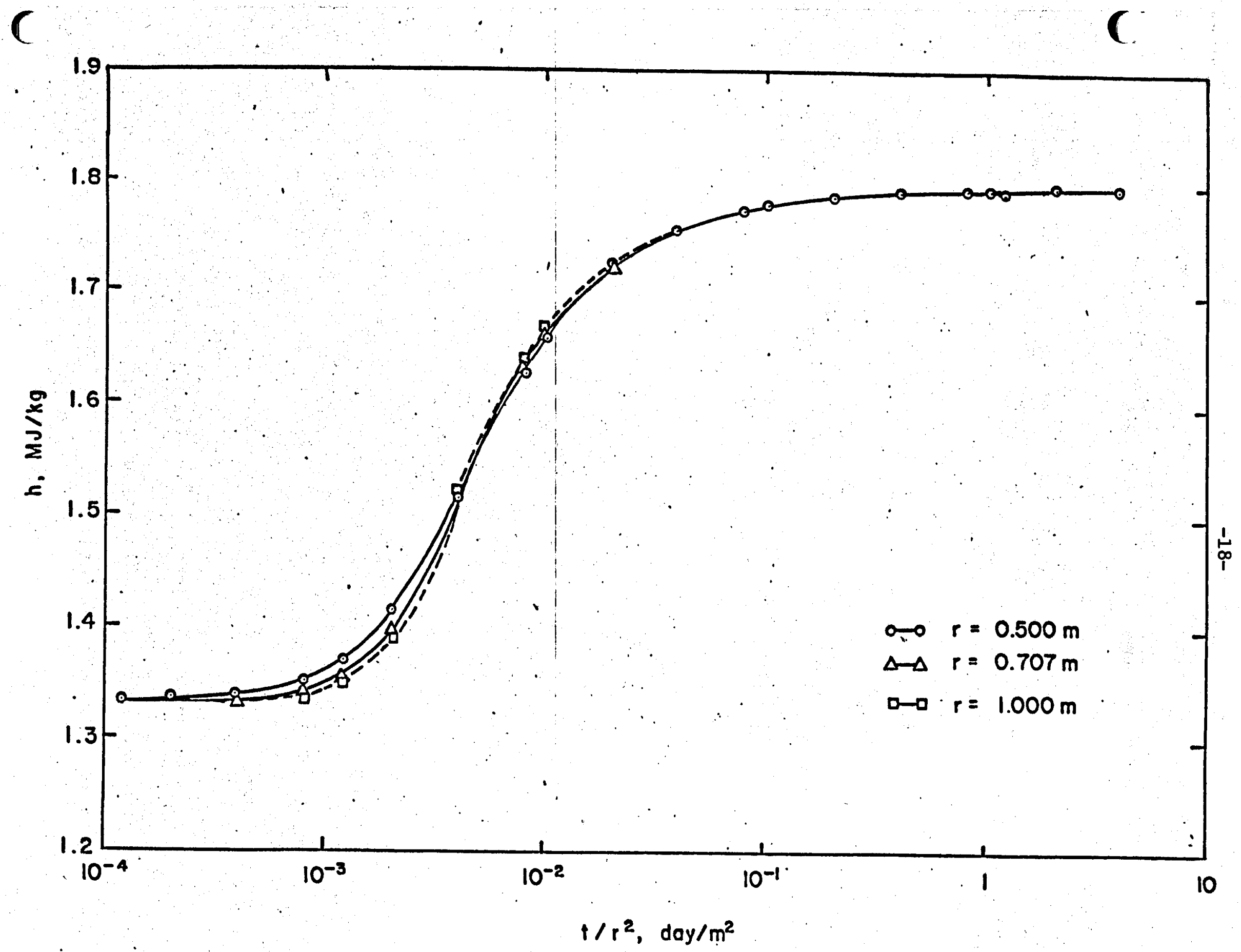

FIG. 2.5: PROBLEM 2(b) 
TABLE 2.3: PROBLEM 2(c)

\begin{tabular}{|c|c|c|c|c|c|c|c|c|c|}
\hline \multirow{2}{*}{$t / \mathrm{r}^{2}\left(\mathrm{Day} / \mathrm{m}^{2}\right)$} & \multicolumn{3}{|c|}{$x-0.5 m$} & \multicolumn{3}{|c|}{$r=0.707 \mathrm{~m}$} & \multicolumn{3}{|c|}{$x=1.0 \mathrm{~m}$} \\
\hline & $\stackrel{P}{P}$ & s & $\begin{array}{c}\mathrm{h} \\
(\mathrm{MJ} / \mathrm{kg})\end{array}$ & $\mathbf{P}$ & $s$ & h & $\mathbf{P}$ & $\mathbf{s}$ & h \\
\hline 0.00001 & - & - & - & - & - & - & 8.9304 & 1.0 & 1.3408 \\
\hline 0.00002 & - & - & - & 8.8486 & 1.0 & 1.3408 & 8.8482 & 1.0 & 1.3407 \\
\hline 0.00004 & 8.7266 & 1.0 & 1.3407 & 8.7647 & 1.0 & 1.3407 & 8.7776 & 1.0 & 1.3407 \\
\hline 0.00008 & 8.6992 & 1.0 & 1.3405 & 8.6840 & 1.0 & 1.3406 & 8.7127 & 1.0 & 1.3406 \\
\hline 0.00012 & 8.6238 & 1.0 & 1.3406 & 8.6357 & 1.0 & 1.3406 & 8.6949 & 1.0 & 1.3406 \\
\hline 0.00020 & 8.5633 & 1.0 & 1.3405 & 8.6245 & 1.0 & 1.3405 & 8.6791 & 1.0 & 1.3406 \\
\hline 0.0004 & 8.5499 & 0.9995 & 1.3405 & 8.6150 & 1.0 & 1.3405 & 8.6612 & 1.0 & 1.3405 \\
\hline 0.0008 & 8.5487 & 0.9972 & 1.3404 & 8.6038 & 1.0 & 1.3405 & 8.6437 & 1.0 & 1.3405 \\
\hline 0.0012 & 8.5472 & 0.9942 & 1.3404 & 8.5965 & -1.0 & 1.3405 & 8.6315 & 1.0 & 1.3405 \\
\hline 0.0020 & 8.5438 & 0.9876 & 1.3404 & 8.5857 & 1.0 & 1.3405 & 8.6119 & $1: 0$ & 1.3405 \\
\hline 0.004 & 8.5344 & 0.9691 & 1.3404 & 8.5631 & 1.0 & 1.3404 & 8.5893 & 1.0 & 1.3405 \\
\hline 0.008 & 8.5141 & 0.9292 & 1.3404 & 8.5432 & 0.9863 & 1.3404 & 8.5500 & 0.9997 & 1.3404 \\
\hline 0.01 & 8.5037 & 0.9089 & 1.3404 & 8.5338 & 0.9677 & 1.3404 & 8.5448 & 0.9895 & 1.3404 \\
\hline 0.02 & 8.4632 & 0.8346 & 1.3396 & 8.4803 & 0.8623 & 1.3401 & 8.4764 & 0.8560 & 1.3401 \\
\hline 0.04 & 8.3235 & 0.7434 & 1.3405 & 8.2995 & 0.7606 & 1.3413 & 8.2955 & 0.7627 & 1.3418 \\
\hline 0.08 & 7.9319 & 0.7147 & 1.3945 & 7.9363 & 0.7308 & 1.3914 & 7.9328 & 0.7299 & 1.3916 \\
\hline 0.1 & 7.7845 & 0.7208 & 1.3981 & 7.7800 & 0.7308 & 1.3991 & 7.7759 & 0.7311 & 1.3995 \\
\hline 0.2 & 7.3056 & 0.7126 & 1.4245 & 7.3037 & 0.7175 & 1.4235 & 7.3055 & 0.7180 & 1.4227 \\
\hline 0.4 & 6.7808 & 0.7059 & 1.4327 & 6.7854 & 0.7072 & 1.4312 & 6.7876 & 0.7074 & 1.4307 \\
\hline 0.8 & 6.2175 & 0.6969 & 1.4329 & 6.2208 & 0.6968 & 1.4323 & 6.2220 & 0.6969 & 1.4322 \\
\hline 1.0 & 6.1449 & 0.6895 & 1.4394 & 6.1427 & 0.6911 & 1.4901 & 6.1416 & 0.6910 & 1.4404 \\
\hline 1.2 & 5.6994 & 0.6671 & 1.5050 & 5.6973 & 0.6691 & 1.5051 & - & - & - \\
\hline 2.0 & 5.4969 & 0.6768 & 1.4481 & 5.4951 & 0.6780 & 1.4485 & - & - & - \\
\hline 4.0 & 4.7671 & 0.6631 & 1.4549 & - & - & - & - & - & - \\
\hline
\end{tabular}


C

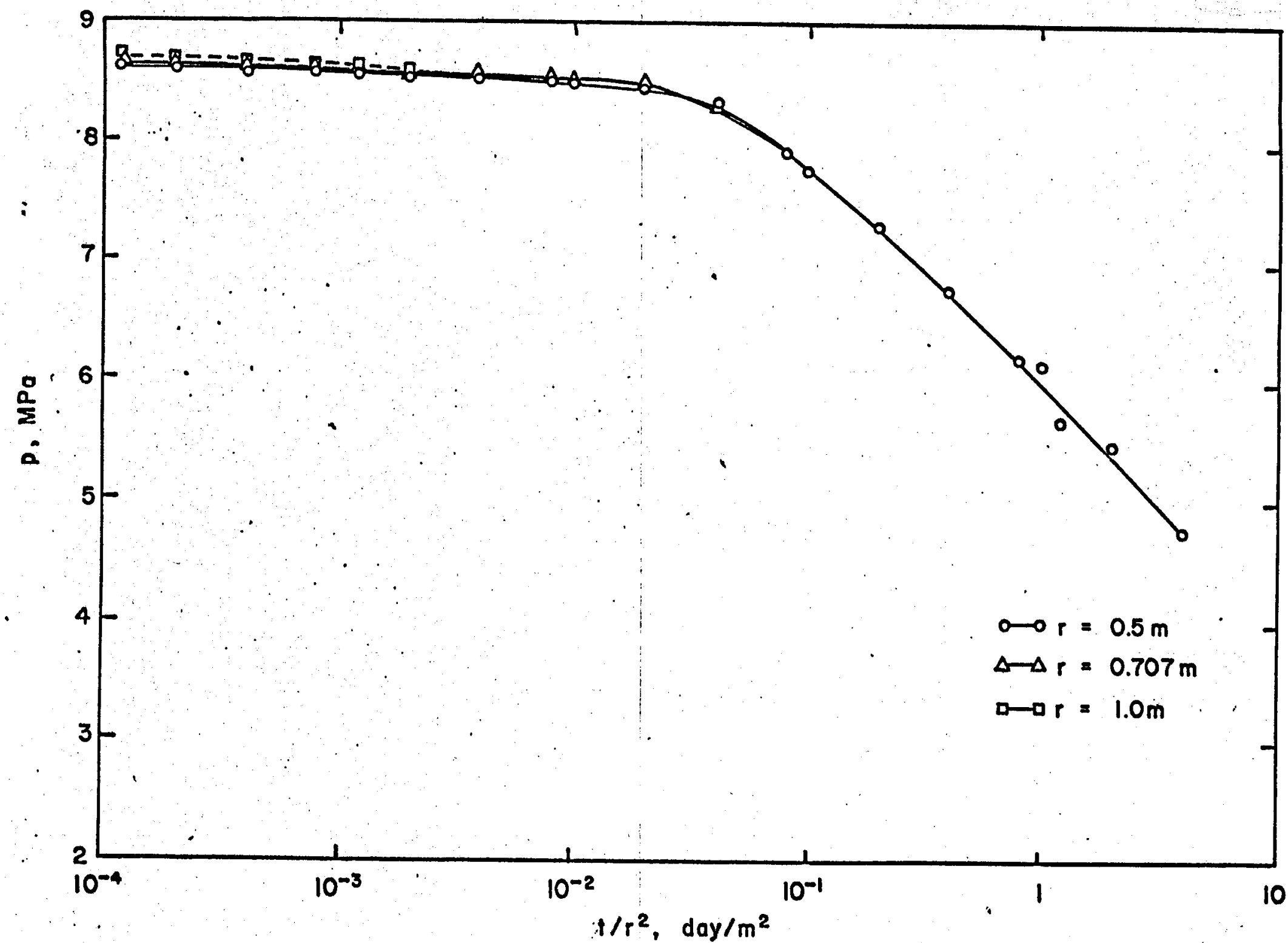

FIG. 2.6: PROBLEM 2(c) 


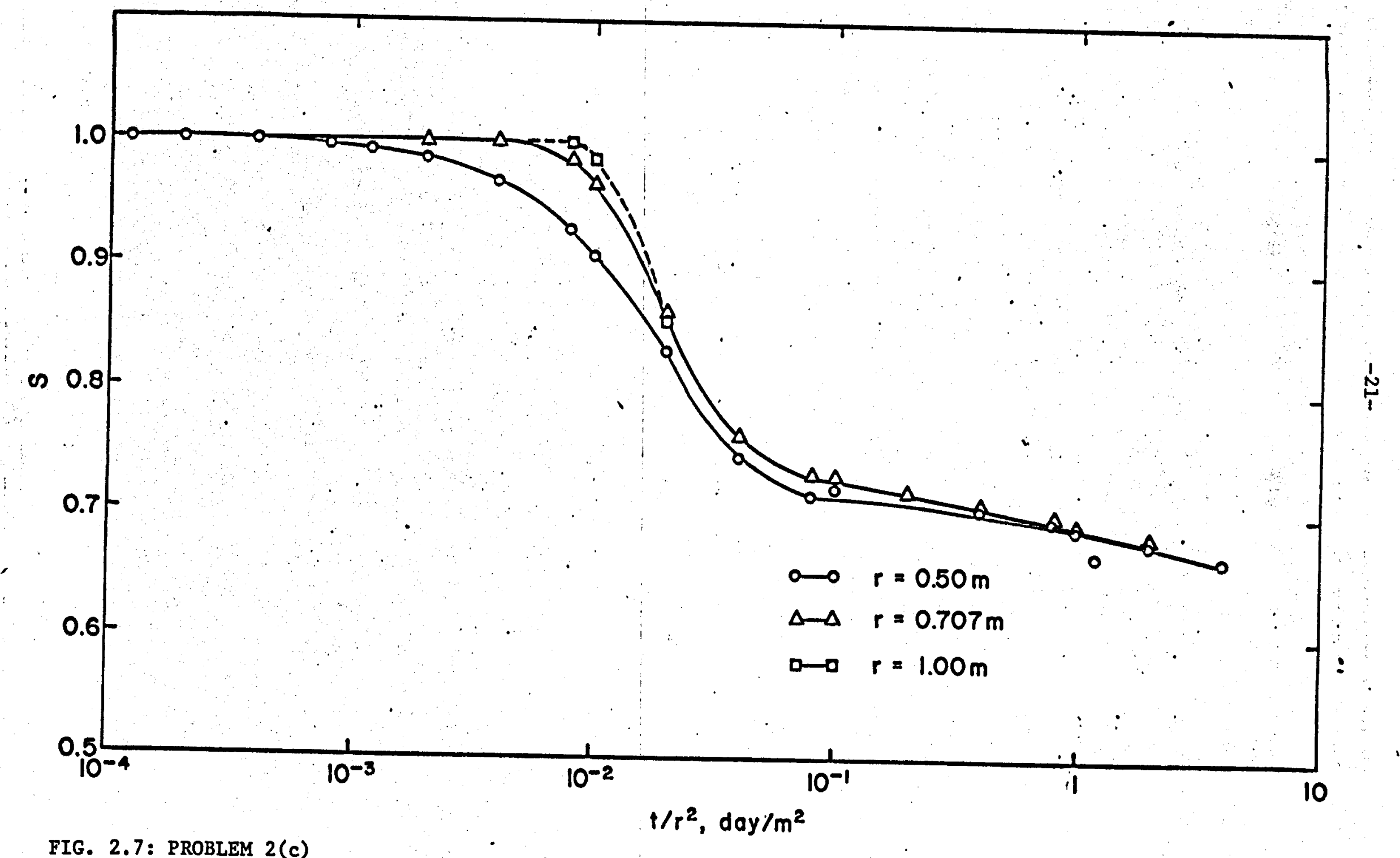




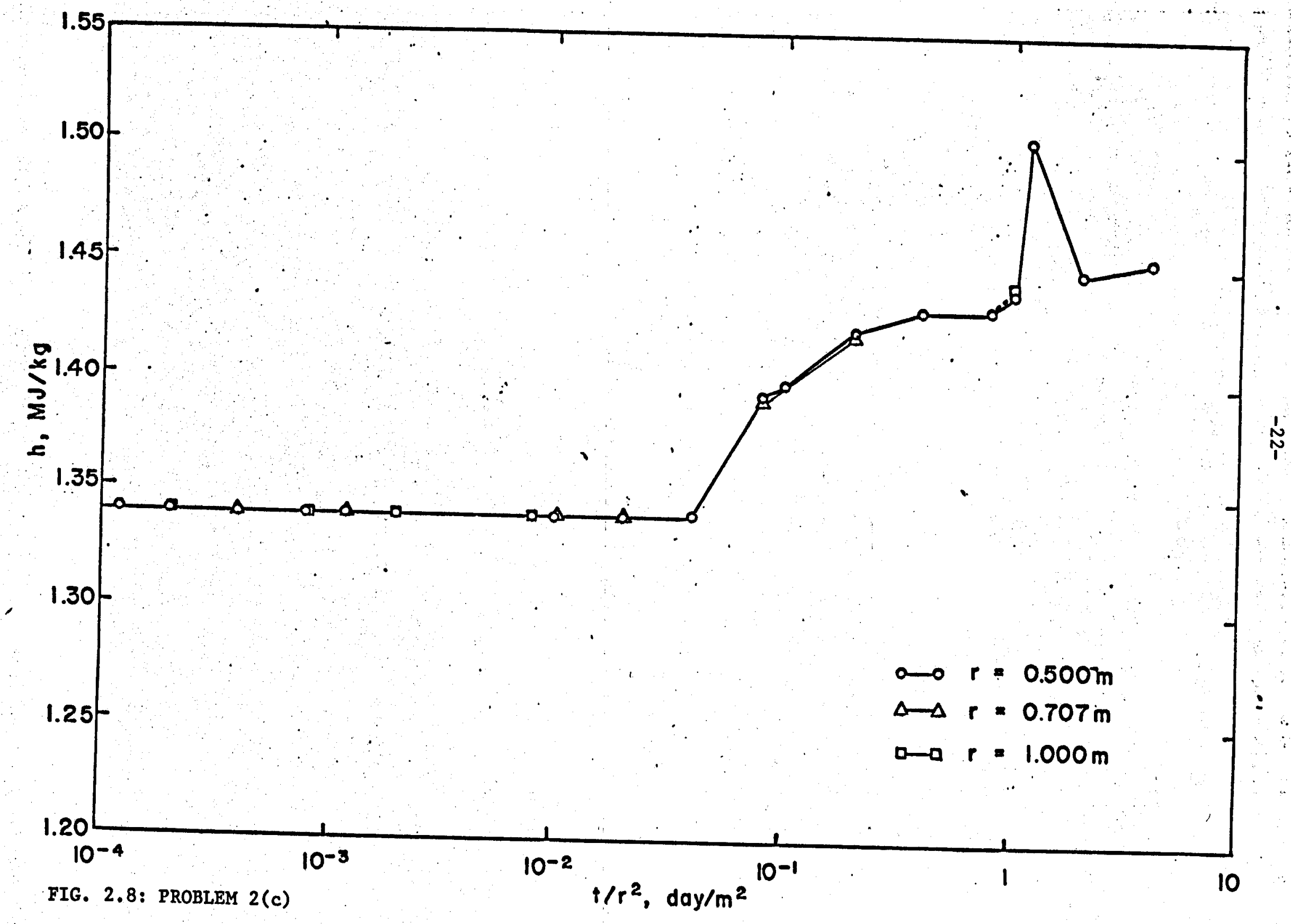


TABLE 2.4: PROBLEM 2(d), ONE NODE CASE

\begin{tabular}{|c|c|c|c|}
\hline $\begin{array}{c}\text { Time, } t \\
\text { (Days) }\end{array}$ & $\begin{array}{c}\text { Pressure, } \\
\text { (MPa) }\end{array}$ & Saturation, S & $\begin{array}{c}\text { Flowing } \\
\text { Enthalpy } \mathrm{h} \\
\text { MJ/kg }\end{array}$ \\
\hline .0001 & 2.9957 & 0.6461 & 1.3437 \\
.0002 & 2.9912 & 0.6422 & 1.3652 \\
.0004 & 2.9813 & 0.6345 & 1.4114 \\
.0008 & 2.9579 & 0.6189 & 1.5164 \\
.0012 & 2.9291 & 0.6033 & 1.6377 \\
.002 & 2.8532 & 0.5718 & 1.9163 \\
.004 & 2.5590 & 0.4924 & 2.5445 \\
.006 & 2.1908 & 0.4138 & 2.7720 \\
.008 & 1.8286 & 0.3373 & 2.7987 \\
.010 & 1.4955 & 0.2630 & 2.7958 \\
.011 & 1.3414 & 0.2267 & 2.7935 \\
\hline
\end{tabular}




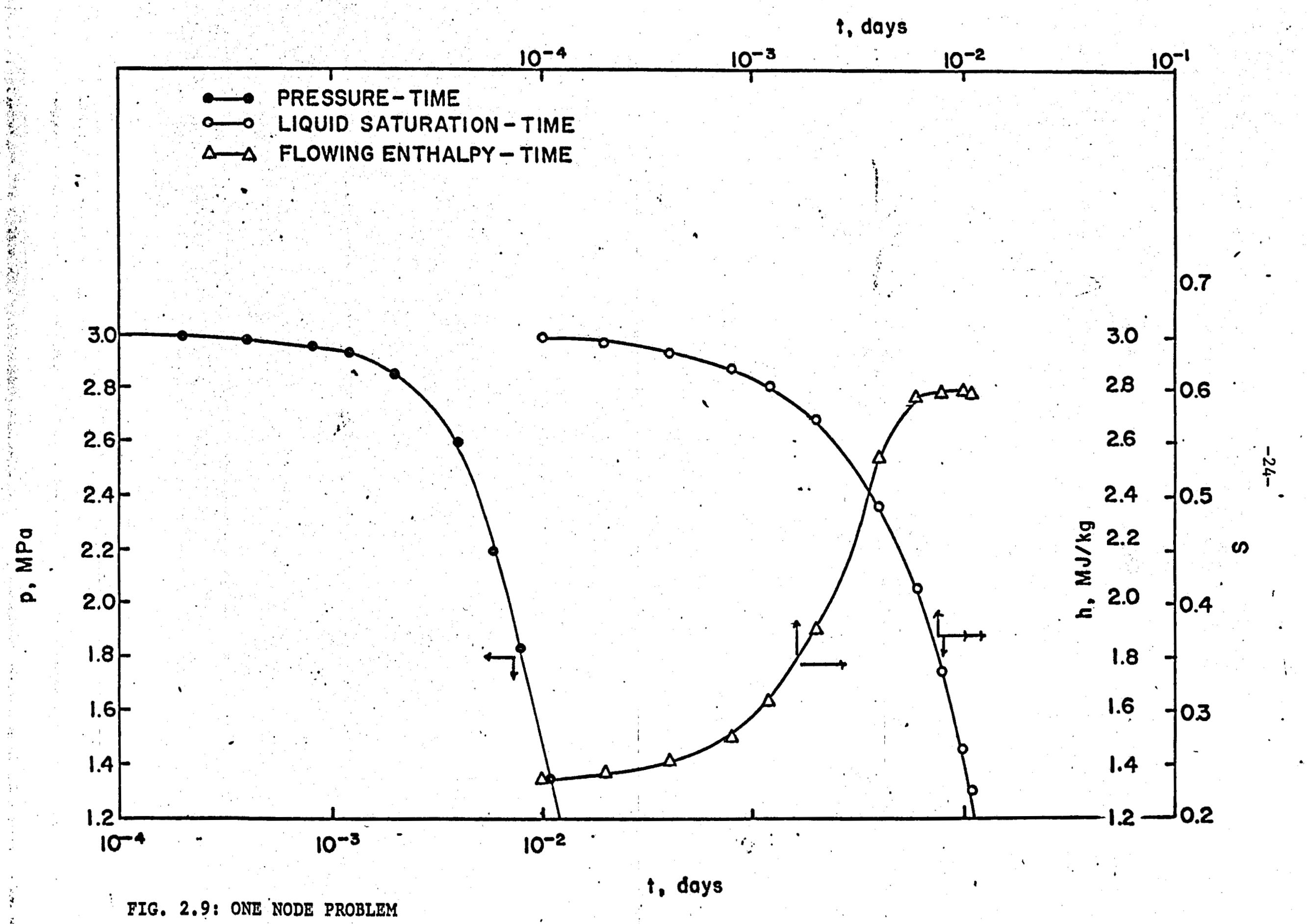


rectangular meshes only. To achieve the single protruding well block, it was necessary to include an entire column of 11 nodes, the upper 10 of which were then given zero transmissabilities in all directions.

The problem statement did not specifically state whether or not gravity effects were to be included. Both cases were tried with and without gravity with essentially identical results. Case a showed a $0.01 \%$ change in some properties at later times when gravity was added; however, the solution was also marginally less stable numerically, which could have given rise to this very small difference. In Case $b$, there was no difference in any parameter at any time between the gravity included and gravity excluded cases.

The time differencing scheme suggested in the problem statement proved to be insufficient to ensure stability of the solution. The scheme used was an initial time step of $10^{-5}$ days $(0.864$ secs) with a constant multiplying factor of 1.04 (instead of the 1.05 suggested) at each subsequent time step. The number of time steps required to reach $10^{4} \operatorname{secs}$ was then 140 .

The pressures at the well and at the $(2.5,0.25)$ node are tabulated for Case a in Table 3.1, and graphed in Figs. 3.1 and 3.2 , respectively. The same two pressures for Case b are tabulated in Table 3.2 and graphed In Figs. 3.3 and 3.4. The saturation at the $(2,5,0,25)$ node for Case b... is also tabulated in Table 3.2 .

\subsection{Problem No. 4: 2-Phase System with Drainage}

This problem was the only one of the five which included the effects of gravity. Boiling occurs in the hydrostatic column of liquid due to production at the bottom; and cold water is drawn in at the top. 
TABLE 3.1: PROBLEM 3(a)

\begin{tabular}{|c|c|c|}
\hline Time (Secs) & $\begin{array}{l}\text { Pressure } \\
\text { at Well } \\
(\mathrm{MPa})\end{array}$ & $\begin{array}{c}\text { Pressure } \\
\text { at } \\
(2.5,0.25) \\
(\mathrm{MPa})\end{array}$ \\
\hline 0.864 & 2.949 & 3.05 \\
\hline 2.6784 & 2.835 & 3.05 \\
\hline 4.6656 & 2.802 & 3.05 \\
\hline 6.8256 & 2.766 & 3.05 \\
\hline 9.1584 & 2.748 & 3.05 \\
\hline 11.664 & 2.733 & 3.05 \\
\hline 14.3424 & 2.722 & 3.05 \\
\hline 17.28 & 2.711 & 3.05 \\
\hline 27.648 & 2.686 & 3.04 \\
\hline 45.792 & 2.654 & 3.034 \\
\hline 63.6768 & 2.635 & 3.030 \\
\hline 86.2272 & 2.618 & 3.020 \\
\hline 104.544 & 2.606 & 3.013 \\
\hline 138.0672 & 2.586 & 3.003 \\
\hline 180.4032 & 2.566 & 2.988 \\
\hline 457.1424 & 2.473 & 2.919 \\
\hline 744.8544 & 2.427 & 2.877 \\
\hline 875.0592 & 2.412 & 2.861 \\
\hline 1792.2816 & 2.321 & 2.792 \\
\hline 2667.168 & 2.278 & 2.757 \\
\hline 4283.1936 & 2.233 & 2.717 \\
\hline 6870.528 & 2.185 & 2.666 \\
\hline 8699.184 & 2.137 & 2.637 \\
\hline 9410.7744 & 2.132 & 2.633 \\
\hline 10180.426 & 2.121 & 2.624 \\
\hline
\end{tabular}




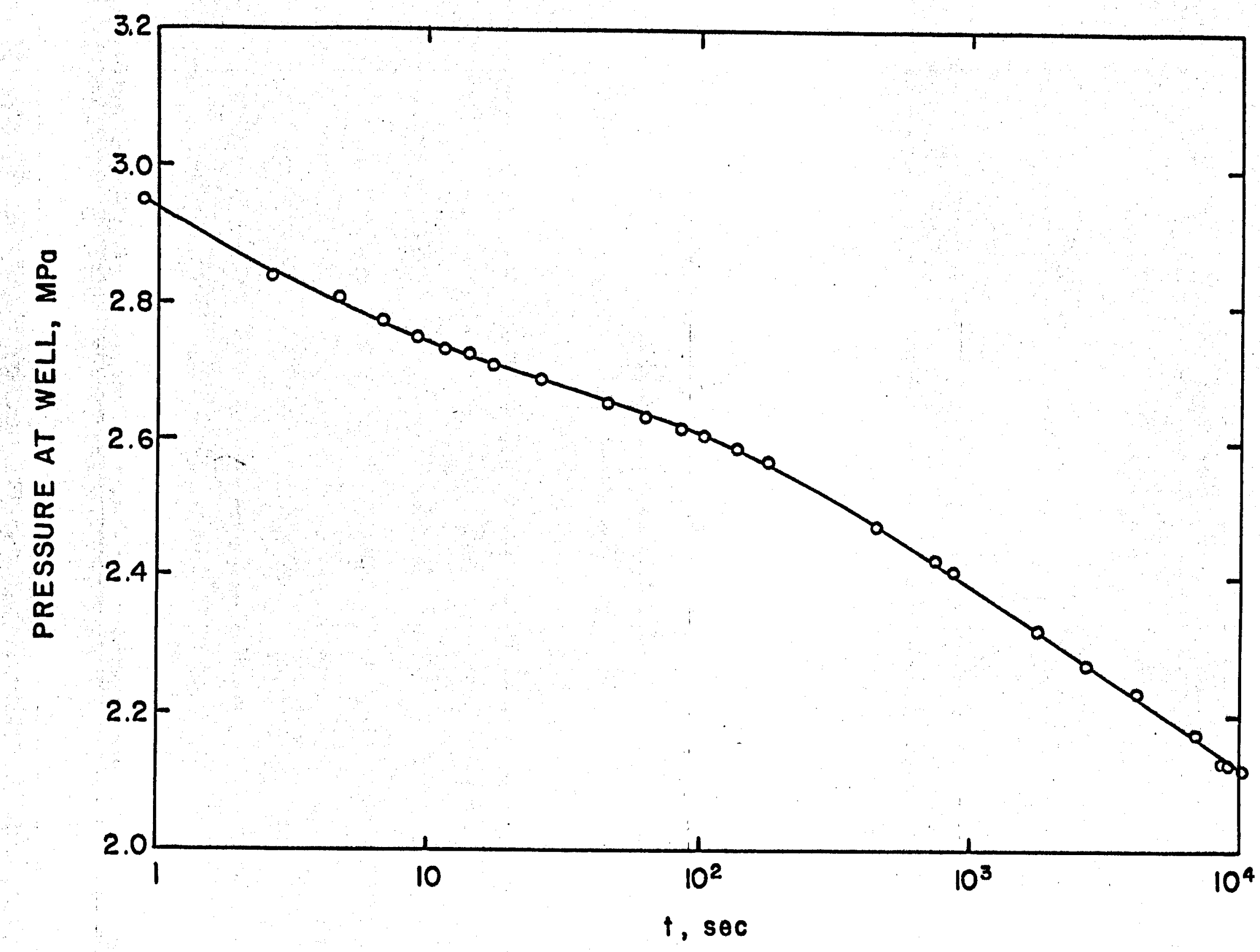

FIG. 3.1: PROBLEM 3(a) 


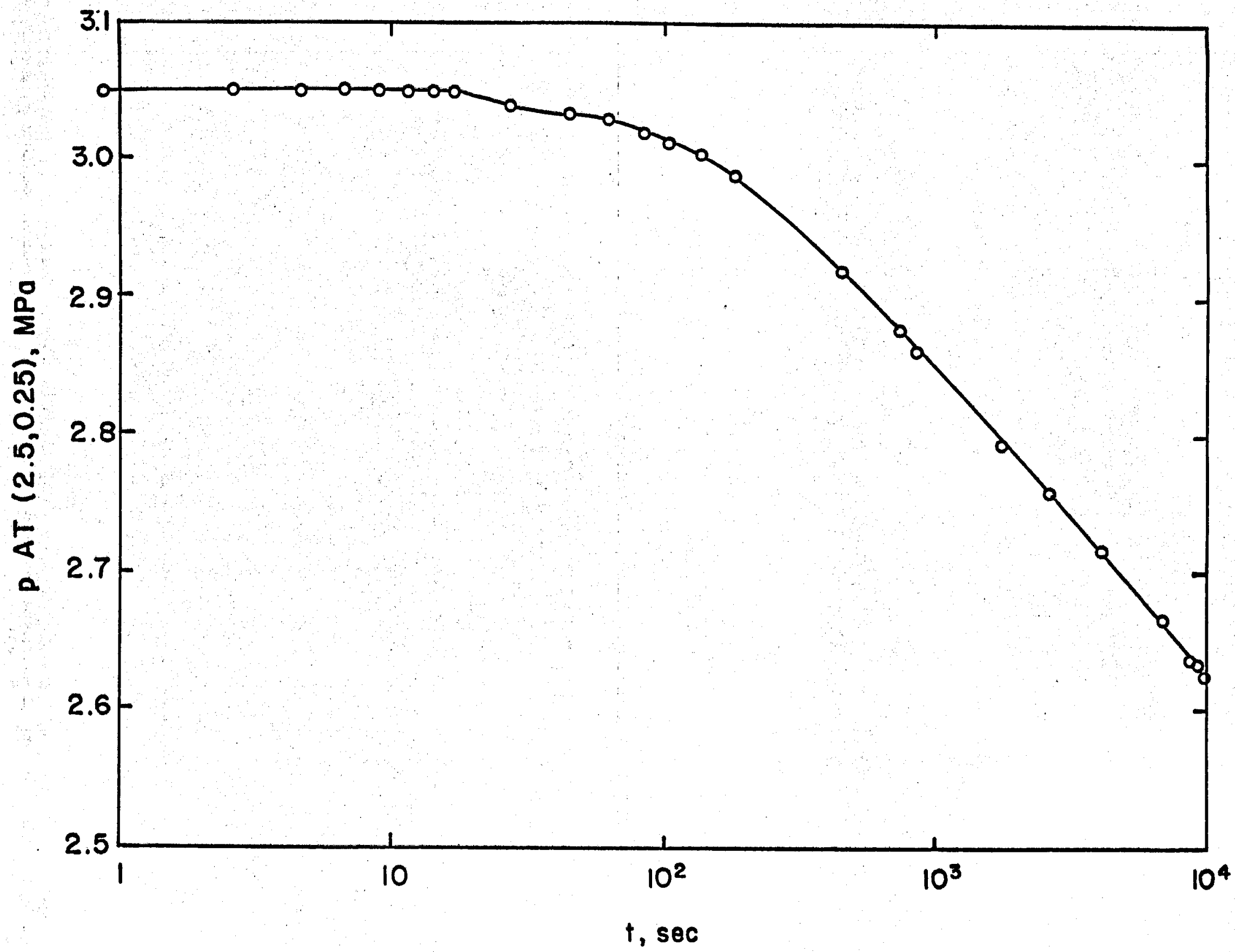

FIG. 3.2: PROBLEM 3(a) 
TABLE 3.2: PROBLEM 3(b)

\begin{tabular}{|c|c|c|c|}
\hline Time (Secs) & $\begin{array}{l}\text { Pressure } \\
\text { at We1l } \\
\text { (MPa) }\end{array}$ & $\begin{array}{c}\text { Pressure } \\
\text { at }(2.5,0.25) \\
(\mathrm{MPa})\end{array}$ & $\begin{array}{c}\text { Saturation } \\
\text { at } \\
(2.5,0.25)\end{array}$ \\
\hline 0.864 & 3.004 & 3.05 & 0.2 \\
\hline 2.6784 & 2.956 & 3.05 & 0.2 \\
\hline 4.6656 & 2.946 & 3.05 & 0.2 \\
\hline 6.8256 & 2.931 & 3.05 & 0.2 \\
\hline 9.1584 & 2.918 & 3.05 & 0.2 \\
\hline 11.664 & 2.906 & 3.05 & 0.2 \\
\hline 14.3424 & 2.895 & 3.05 & 0.2 \\
\hline 17.28 & 2.885 & 3.05 & 0.2 \\
\hline 27.648 & 2.860 & 3.05 & 0.2 \\
\hline 45.792 & 2.834 & 3.05 & 0.2 \\
\hline 63.6768 & 2.818 & 3.05 & 0.2 \\
\hline 86.2272 & 2.803 & 3.05 & 0.2 \\
\hline 104.544 & 2.793 & 3.05 & 0.2 \\
\hline 138.0672 & 2.779 & 3.05 & 0.1999 \\
\hline 180.4032 & 2.765 & 3.05 & 0.1999 \\
\hline 457.1424 & 2.717 & 3.047 & 0.1989 \\
\hline 744.8544 & 2.692 & 3.042 & 0.1974 \\
\hline 875.0592 & 2.684 & 3.040 & 0.1968 \\
\hline 1792.2816 & 2.648 & 3.026 & 0.1924 \\
\hline 2667.168 & 2.628 & 3.015 & 0.1891 \\
\hline 4283.1936 & 2.601 & 2.999 & 0.1840 \\
\hline 6870.528 & 2.568 & 2.976 & 0.1771 \\
\hline 8699.184 & 2.550 & 2.963 & 0.1729 \\
\hline 9410.7744 & 2.543 & 2.958 & 0.1713 \\
\hline 10180.426 & 2.536 & 2.952 & 0.1697 \\
\hline
\end{tabular}




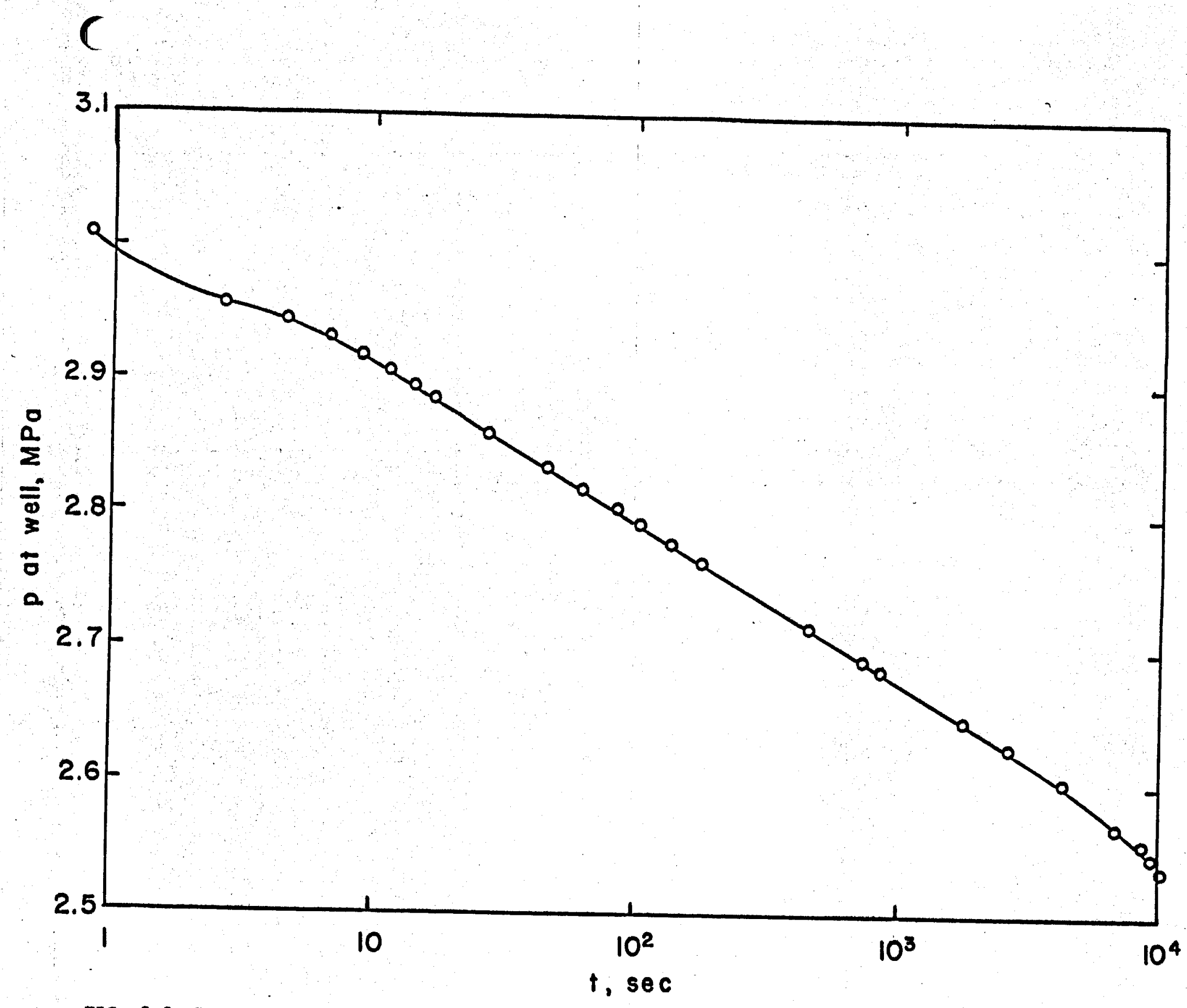

FIG. 3.3: PROBLEM 3(b) 


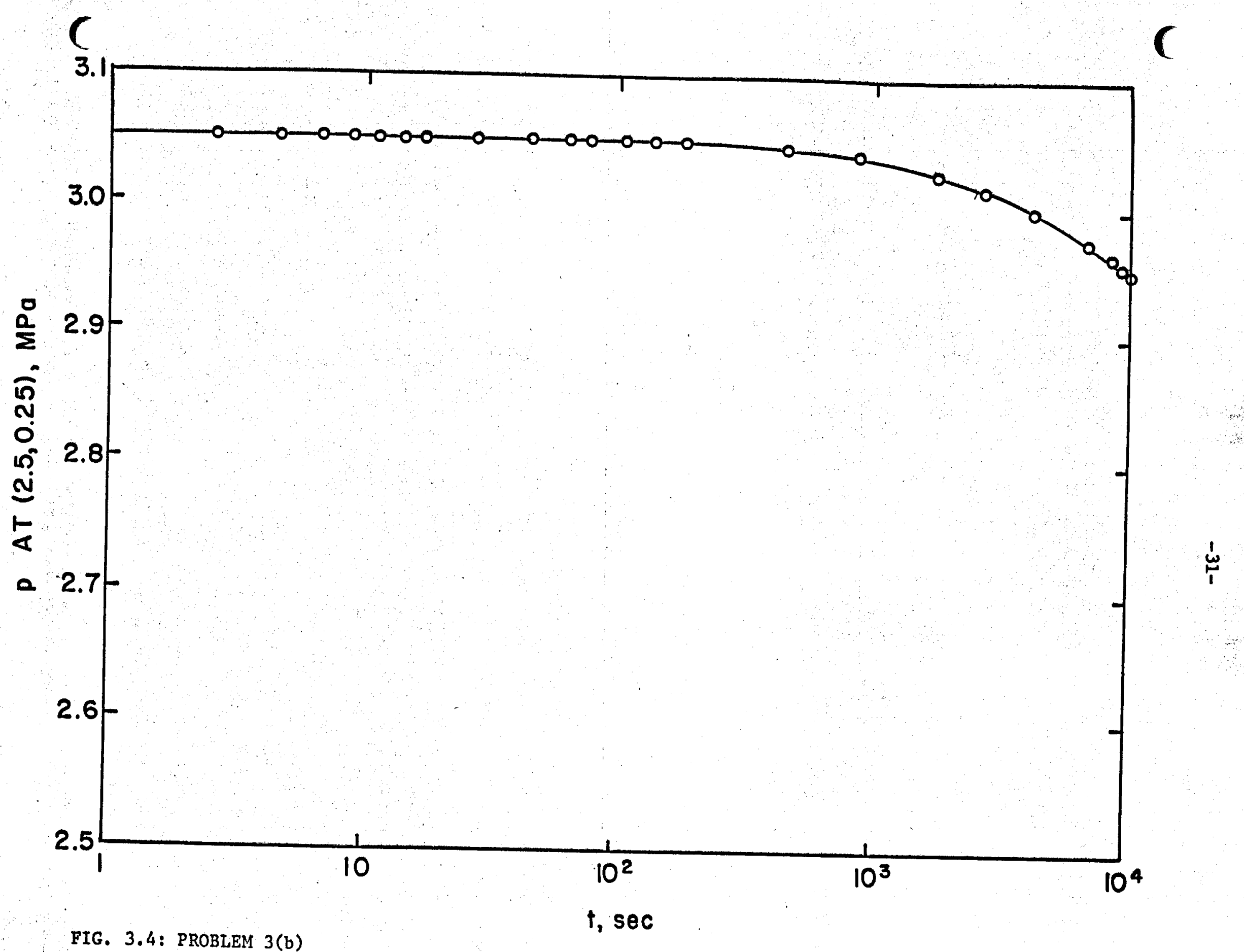


The problem is one-dimensional; however, the program does require a cross-sectional area in the other dimension. The solution was set up as a cylinder of radius $2 \cdot \mathrm{km}$; that is, an area $12.566 \mathrm{~km}^{2}$.

In order to achleve the constant pressure and temperature inlet conditions, a thin $\left(10^{-5} \mathrm{~m}\right)$ grid block was added to the top of the mesh $(D=0)$, and its pressure and temperature held constant.

The time sequence consisted of 10 time steps of 0.1 day, followed by 9 of 1 day, 93 of 2 days, 120 of 5 days, and the remainder (up to 40 years) of 10 days.

The history of discharge enthalpy at $D=2 \mathrm{~km}$, recharge rate, and cumulative recharge at $D=0$ are tabulated in Table 4.1 and graphed in Figs. $4.1,4.2$, and 4.3 , respectively.

For the graph of pressure, temperature, and saturation, it was not possible to determine these values at the specified depths of $0.5,1.0$, 1.5 , and $2.0 \mathrm{~km}$ because the grid specified did not have nodes at these points. The parameters are therefore tabulated for $D=0.55,1.05,1.55$, and $1.95 \mathrm{~km}$ in Table 4.2. Values of saturation not listed in the table are all 1.0.

Pressure/time curves are graphed in Fig. 4.4, temperature/time curves are graphed in Fig. 4.5, and saturation/time curves are graphed in Fig. 4.6.

\subsection{Problem No. 5: Flow in a 2-D Areal Reservoir}

This problem also proved difficult in terms of time step selection, since in both Cases $a$ and $b$ there were times at which the solution became numerically unstable due to rapid changes of condition in the model reservoir. In neither case did these changes become evident in the specified output variables; however, there were reproducible events which occurred 
TABLE 4.1: PROBLEM 4

\begin{tabular}{|c|c|c|c|}
\hline $\begin{array}{l}\text { Time } \\
\text { (Days) }\end{array}$ & $\begin{array}{r}\text { Discharge } \\
\text { Enthalpy } \\
(\mathrm{MJ} / \mathrm{kg})\end{array}$ & $\begin{array}{c}\text { Recharge Rate } \\
(\mathrm{kg} / \mathrm{s})\end{array}$ & $\begin{array}{c}\text { Cumulative } \\
\text { Recharge } \\
\text { (kg) }\end{array}$ \\
\hline $\begin{array}{l}1 \\
2 \\
4 \\
6 \\
8 \\
10 \\
14 \\
20 \\
30 \\
40 \\
60 \\
90 \\
120 \\
150 \\
180 \\
210 \\
270 \\
365 \\
450 \\
550 \\
730 \\
1000 \\
1500 \\
2000 \\
2500 \\
3000 \\
3650 \\
4000 \\
7300 \\
10000 \\
10950 \\
12000 \\
14000 \\
14600\end{array}$ & $\begin{array}{l}1.3958 \\
1.3958 \\
1.3957 \\
1.3955 \\
1.3954 \\
1.3953 \\
1.3951 \\
1.3948 \\
1.3942 \\
1.3937 \\
1.3932 \\
1.3931 \\
1.3930 \\
1.3930 \\
1.3929 \\
1.3928 \\
1.3927 \\
1.3925 \\
1.3923 \\
1.3920 \\
1.3915 \\
1.3907 \\
1.3894 \\
1.3882 \\
1.3871 \\
1.3859 \\
1.3844 \\
1.3836 \\
1.3760 \\
1.3688 \\
1.3600 \\
1.3339 \\
2.1502 \\
2.5037\end{array}$ & $\begin{array}{l}0.3255 \mathrm{E}-03 \\
0.1360 \mathrm{E}-02 \\
0.5903 \mathrm{E} 00 \\
0.2298 \mathrm{E} 01 \\
0.6370 \mathrm{E} 01 \\
0.1269 \mathrm{E} 02 \\
0.2513 \mathrm{E} 02 \\
0.5699 \mathrm{E} 02 \\
0.1164 \mathrm{E} 03 \\
0.1755 \mathrm{E} 03 \\
0.2776 \mathrm{E} 03 \\
0.3038 \mathrm{E} 03 \\
0.3059 \mathrm{E} 03 \\
0.3074 \mathrm{E} 03 \\
0.3089 \mathrm{E} 03 \\
0.3103 \mathrm{E} 03 \\
0.3133 \mathrm{E} 03 \\
0.3181 \mathrm{E} 03 \\
0.3225 \mathrm{E} 03 \\
0.3285 \mathrm{E} 03 \\
0.3432 \mathrm{E} 03 \\
0.3823 \mathrm{E} 03 \\
0.3945 \mathrm{E} 03 \\
0.3762 \mathrm{E} 03 \\
0.3751 \mathrm{E} 03 \\
0.3757 \mathrm{E} 03 \\
0.3673 \mathrm{E} 03 \\
0.3717 \mathrm{E} 03 \\
0.3491 \mathrm{E} 03 \\
0.3310 \mathrm{E} 03 \\
0.3219 \mathrm{E} 03 \\
0.3125 \mathrm{E} 03 \\
0.3080 \mathrm{E} 03 \\
0.3321 \mathrm{E} 03 \\
0.3\end{array}$ & $\begin{array}{l}0.1760 \mathrm{E} 02 \\
0.1553 \mathrm{E} 03 \\
0.7089 \mathrm{E} 05 \\
0.3557 \mathrm{E} 06 \\
0.1258 \mathrm{E} 07 \\
0.3131 \mathrm{E} 07 \\
0.1028 \mathrm{E} 08 \\
0.3409 \mathrm{E} 08 \\
0.1139 \mathrm{E} 09 \\
0.2453 \mathrm{E} 09 \\
0.6523 \mathrm{E} 09 \\
0.1424 \mathrm{E} 10 \\
0.2215 \mathrm{E} 10 \\
0.3010 \mathrm{E} 10 \\
0.3809 \mathrm{E} 10 \\
0.4611 \mathrm{E} 10 \\
0.6228 \mathrm{E} 10 \\
0.8820 \mathrm{E} 10 \\
0.1117 \mathrm{E} 11 \\
0.1399 \mathrm{E} 11 \\
0.1920 \mathrm{E} 11 \\
0.2764 \mathrm{E} 11 \\
0.4489 \mathrm{E} 11 \\
0.6148 \mathrm{E} 11 \\
0.7761 \mathrm{E} 11 \\
0.9393 \mathrm{E} 11 \\
0.1146 \mathrm{E} 12 \\
0.1258 \mathrm{E} 12 \\
0.2282 \mathrm{E} 12 \\
0.3075 \mathrm{E} 12 \\
0.3342 \mathrm{E} 12 \\
0.3631 \mathrm{E} 12 \\
0.4158 \mathrm{E} 12 \\
0.4323 \mathrm{E} 12\end{array}$ \\
\hline
\end{tabular}




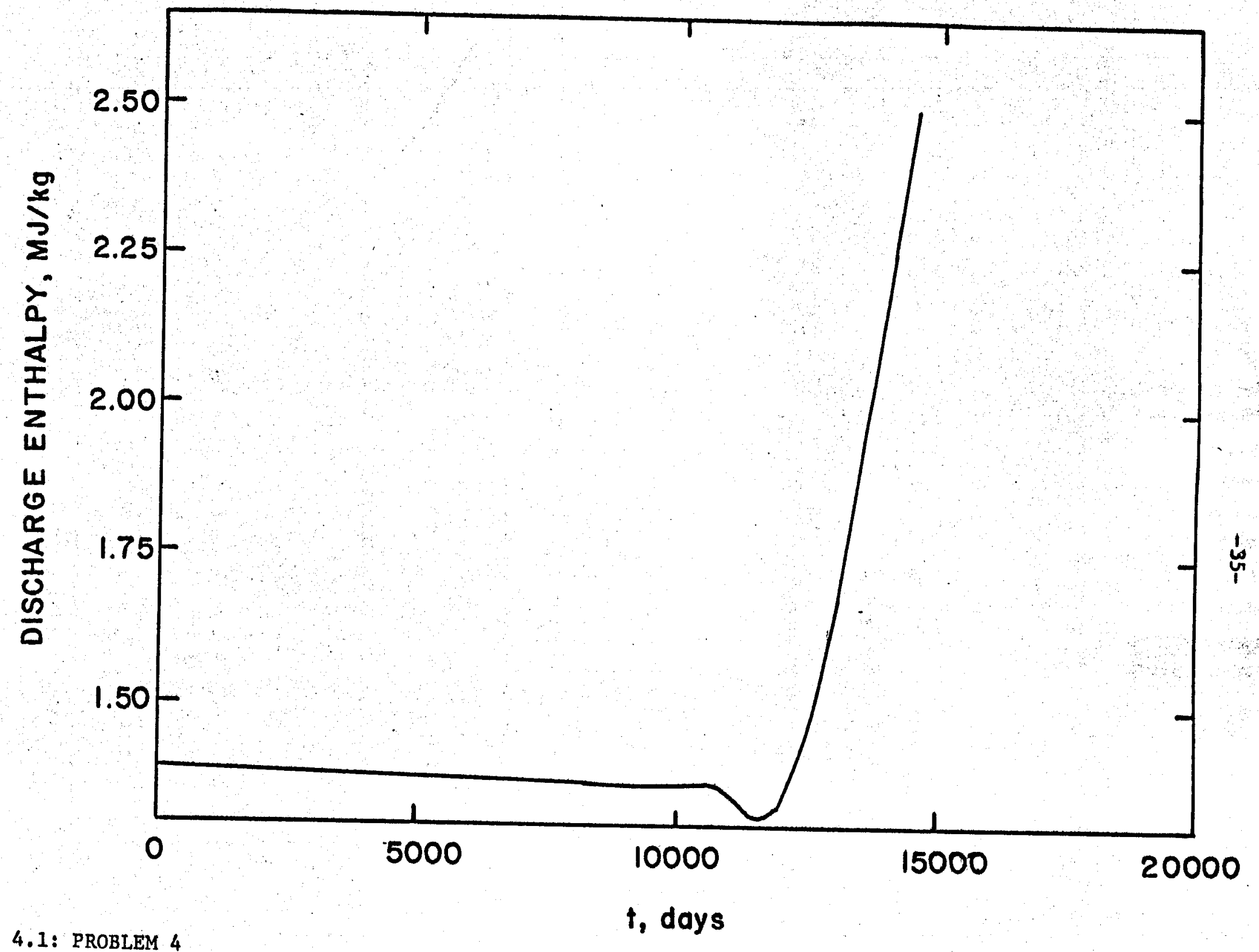

FIG. 4.1: PROBLEM 4 

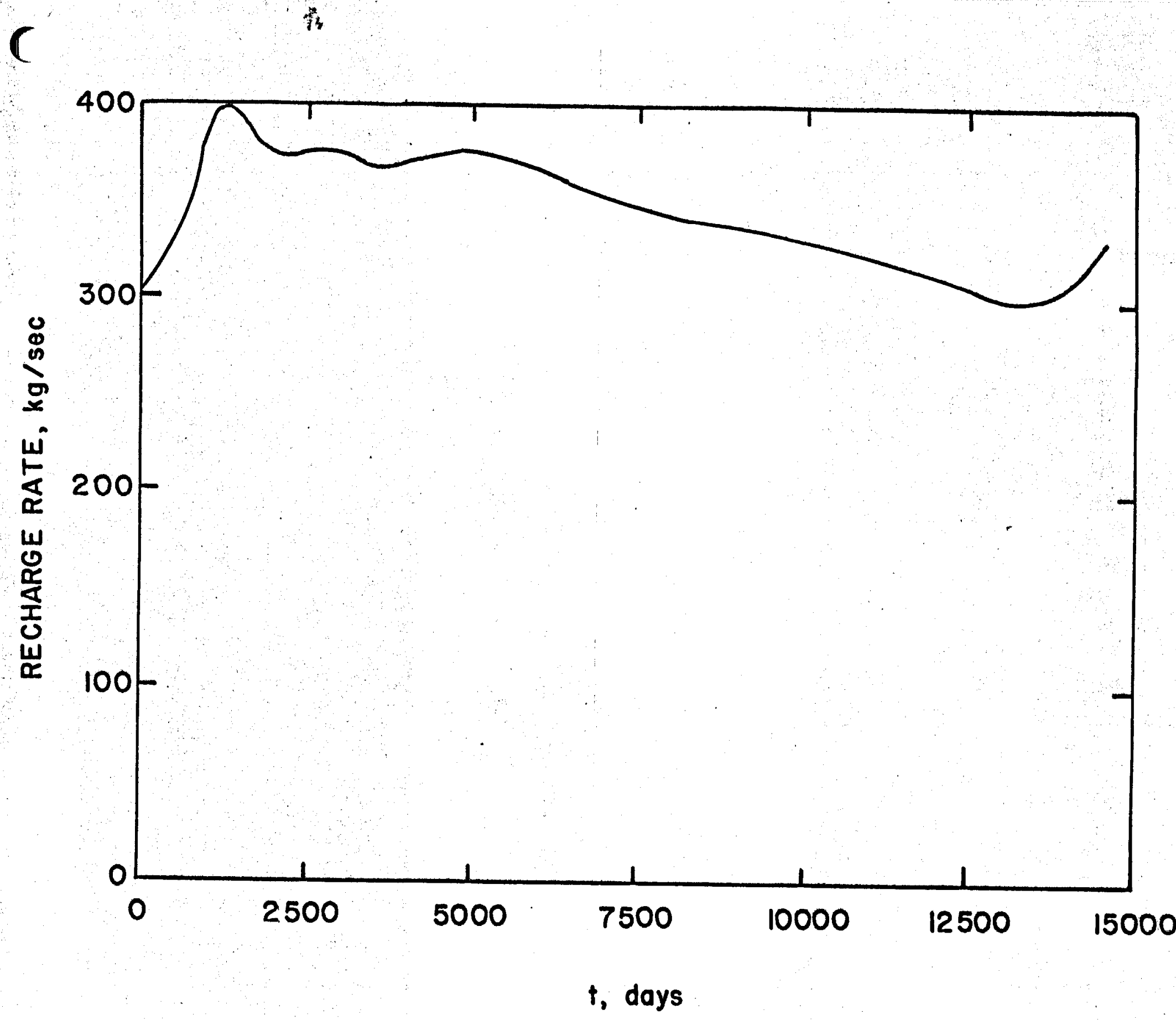

FIG. 4.2: PROBLEM 4 
TABLE 4.2: PROBLEM 4

\begin{tabular}{|c|c|c|c|c|c|c|c|c|c|c|c|c|}
\hline \multirow{2}{*}{$\begin{array}{c}\text { Tlme } \\
t, \text { Days }\end{array}$} & \multicolumn{3}{|c|}{$D=0.55 \mathrm{~km}$} & \multicolumn{3}{|c|}{$D-1.05 \mathrm{~km}$} & \multicolumn{3}{|c|}{$D=1.55 \mathrm{~km}$} & \multicolumn{3}{|c|}{$D=1.95 \mathrm{~km}$} \\
\hline & $\begin{array}{l}\text { Press } \\
\text { P;MPa }\end{array}$ & $\begin{array}{l}\text { Temp. } \\
\mathrm{T} \bullet \mathrm{C}\end{array}$ & $\begin{array}{c}\text { Sat } \\
\mathbf{S}\end{array}$ & $\mathbf{P}$ & $\mathbf{T}$ & $\mathbf{S}$ & $\mathbf{P}$ & $\mathbf{T}$ & $\mathbf{S}$ & $\mathbf{P}$ & $\mathbf{T}$ & $\mathbf{s}$ \\
\hline 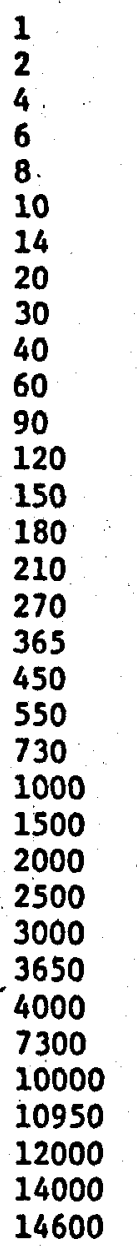 & $\begin{array}{l}5.297 \\
5.296 \\
5.278 \\
5.244 \\
5.201 \\
5.152 \\
5.072 \\
4.903 \\
4.617 \\
4.343 \\
3.924 \\
3.862 \\
3.854 \\
3.846 \\
3.839 \\
3.832 \\
3.817 \\
3.794 \\
3.772 \\
3.742 \\
3.669 \\
3.479 \\
3.418 \\
3.497 \\
3.495 \\
3.485 \\
3.516 \\
3.490 \\
3.560 \\
3.621 \\
3.658 \\
3.697 \\
3.701 \\
3.566\end{array}$ & $\begin{array}{l}164 \\
164 \\
163.999 \\
163.998 \\
163.996 \\
163.994 \\
163.990 \\
163.981 \\
163.965 \\
163.95 \\
163.91 \\
163.88 \\
163.85 \\
163.82 \\
163.79 \\
163.77 \\
163.71 \\
163.62 \\
163.53 \\
163.43 \\
163.24 \\
162.94 \\
162.32 \\
161.75 \\
161.18 \\
160.61 \\
159.88 \\
159.49 \\
155.91 \\
153.15 \\
152.22 \\
151.22 \\
149.40 \\
148.82\end{array}$ & 1 & $\begin{array}{l}9.313 \\
9.291 \\
9.201 \\
9.115 \\
9.032 \\
8.952 \\
8.835 \\
8.612 \\
8.261 \\
7.933 \\
7.565 \\
7.556 \\
7.548 \\
7.539 \\
7.530 \\
7.522 \\
7.504 \\
7.476 \\
7.448 \\
7.410 \\
7.313 \\
7.062 \\
6.883 \\
6.727 \\
6.594 \\
6.641 \\
6.583 \\
6.570 \\
6.651 \\
6.724 \\
6.765 \\
6.824 \\
6.773 \\
6.568\end{array}$ & $\begin{array}{l}290.999 \\
290.999 \\
290.995 \\
290.991 \\
290.987 \\
290.983 \\
290.977 \\
290.964 \\
290.942 \\
290.92 \\
290.87 \\
290.79 \\
290.71 \\
290.63 \\
290.55 \\
290.47 \\
290.31 \\
290.04 \\
289.78 \\
289.43 \\
288.52 \\
286.12 \\
284.38 \\
282.84 \\
281.51 \\
281.98 \\
281.39 \\
281.26 \\
282.08 \\
282.81 \\
283.22 \\
283.80 \\
283.29 \\
281.24\end{array}$ & $\begin{array}{l}1 \\
0.997 \\
0.985 \\
0.973 \\
0.962 \\
0.950 \\
0.938 \\
0.914 \\
0.877 \\
0.844 \\
0.805 \\
0.737 \\
0.653 \\
0.670 \\
0.608 \\
0.560 \\
0.527 \\
0.495 \\
0.492 \\
0.490 \\
0.488 \\
0.488 \\
0.489 \\
0.480 \\
0.471\end{array}$ & $\begin{array}{r}12.843 \\
12.816 \\
12.721 \\
12.633 \\
12.548 \\
12.467 \\
12.349 \\
12.123 \\
11.770 \\
11.439 \\
11.073 \\
11.034 \\
11.026 \\
11.017 \\
11.009 \\
10.999 \\
10.980 \\
10.947 \\
10.915 \\
10.868 \\
10.746 \\
10.499 \\
10.222 \\
9.988 \\
9.846 \\
9.574 \\
9.334 \\
9.178 \\
7.734 \\
6.988 \\
7.004 \\
7.091 \\
6.914 \\
6.640\end{array}$ & $\begin{array}{l}301 \\
300.999 \\
300.998 \\
300.996 \\
300.995 \\
300.993 \\
300.991 \\
300.986 \\
300.977 \\
300.97 \\
300.96 \\
300.94 \\
300.93 \\
300.92 \\
300.91 \\
300.90 \\
300.88 \\
300.85 \\
300.82 \\
300.78 \\
300.72 \\
300.62 \\
300.44 \\
300.27 \\
300.09 \\
299.92 \\
299.68 \\
299.56 \\
292.43 \\
285.41 \\
285.56 \\
286.40 \\
284.69 \\
281.97\end{array}$ & $\begin{array}{l}1: . \\
0.846 \\
0.540 \\
0.495 \\
0.496 \\
0.474 \\
0.452\end{array}$ & $\begin{array}{r}15.583 \\
15.554 \\
15.457 \\
15.368 \\
15.283 \\
15.201 \\
15.082 \\
14.856 \\
14.501 \\
14.169 \\
13.765 \\
13.756 \\
13.748 \\
13.739 \\
13.731 \\
13.722 \\
13.702 \\
13.670 \\
13.637 \\
13.591 \\
13.469 \\
13.222 \\
12.945 \\
12.713 \\
12.571 \\
12.300 \\
12.061 \\
11.906 \\
10.453 \\
9.307 \\
8.918 \\
8.249 \\
6.908 \\
6.553\end{array}$ & $\begin{array}{l}309 \\
309 \\
309 \\
308.999 \\
308.999 \\
308.999 \\
308.998 \\
308.996 \\
308.992 \\
308.99 \\
308.98 \\
308.97 \\
308.96 \\
308.95 \\
308.94 \\
308.92 \\
308.90 \\
308.87 \\
308.84 \\
308.80 \\
308.74 \\
308.64 \\
308.46 \\
308.78 \\
308.11 \\
307.93 \\
307.70 \\
307.57 \\
306.40 \\
305.22 \\
303.07 \\
297.10 \\
284.63 \\
281.09\end{array}$ & $\begin{array}{l}1 \\
0.870 \\
0.840 \\
0.593 \\
0.539\end{array}$ \\
\hline
\end{tabular}


C

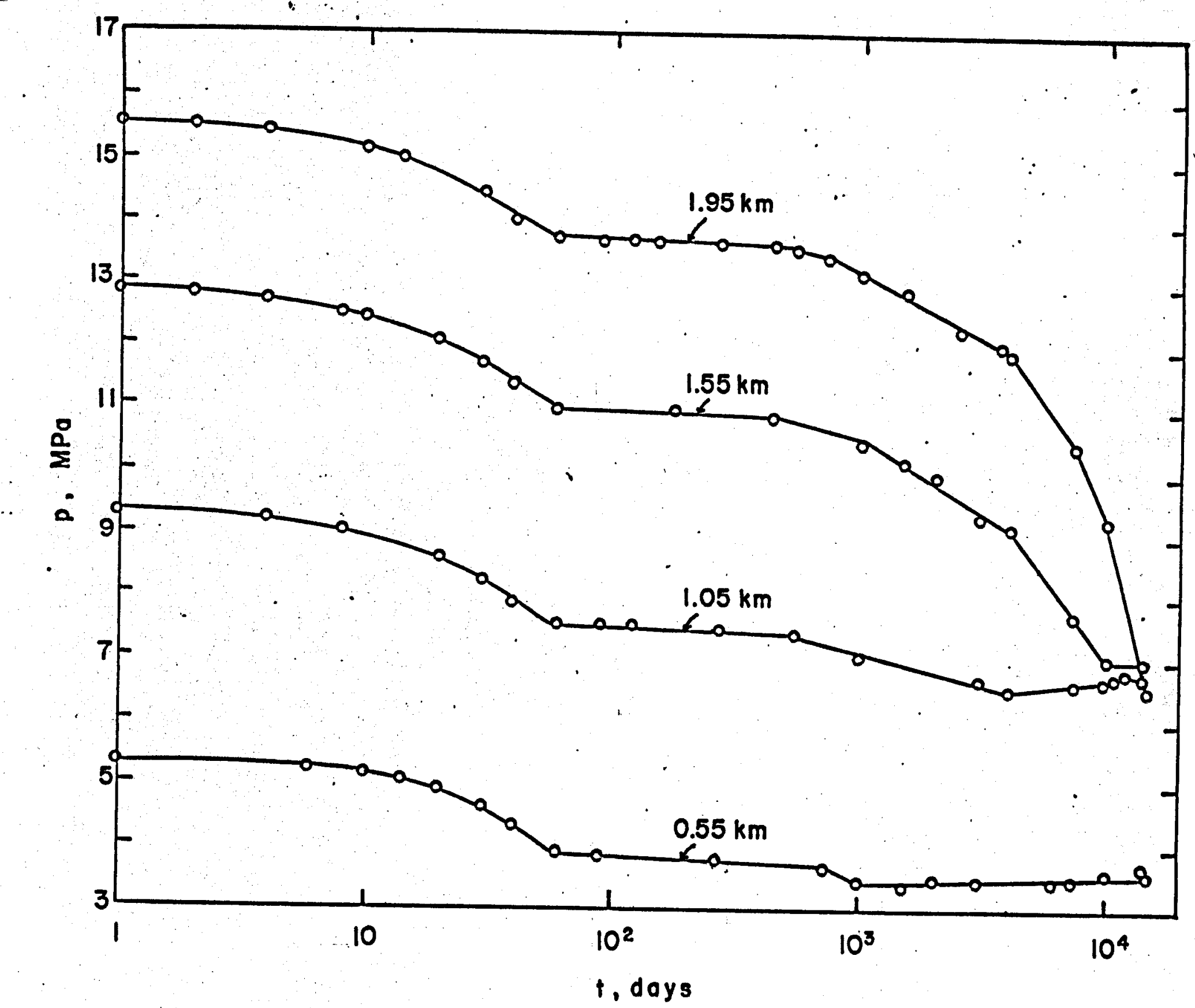




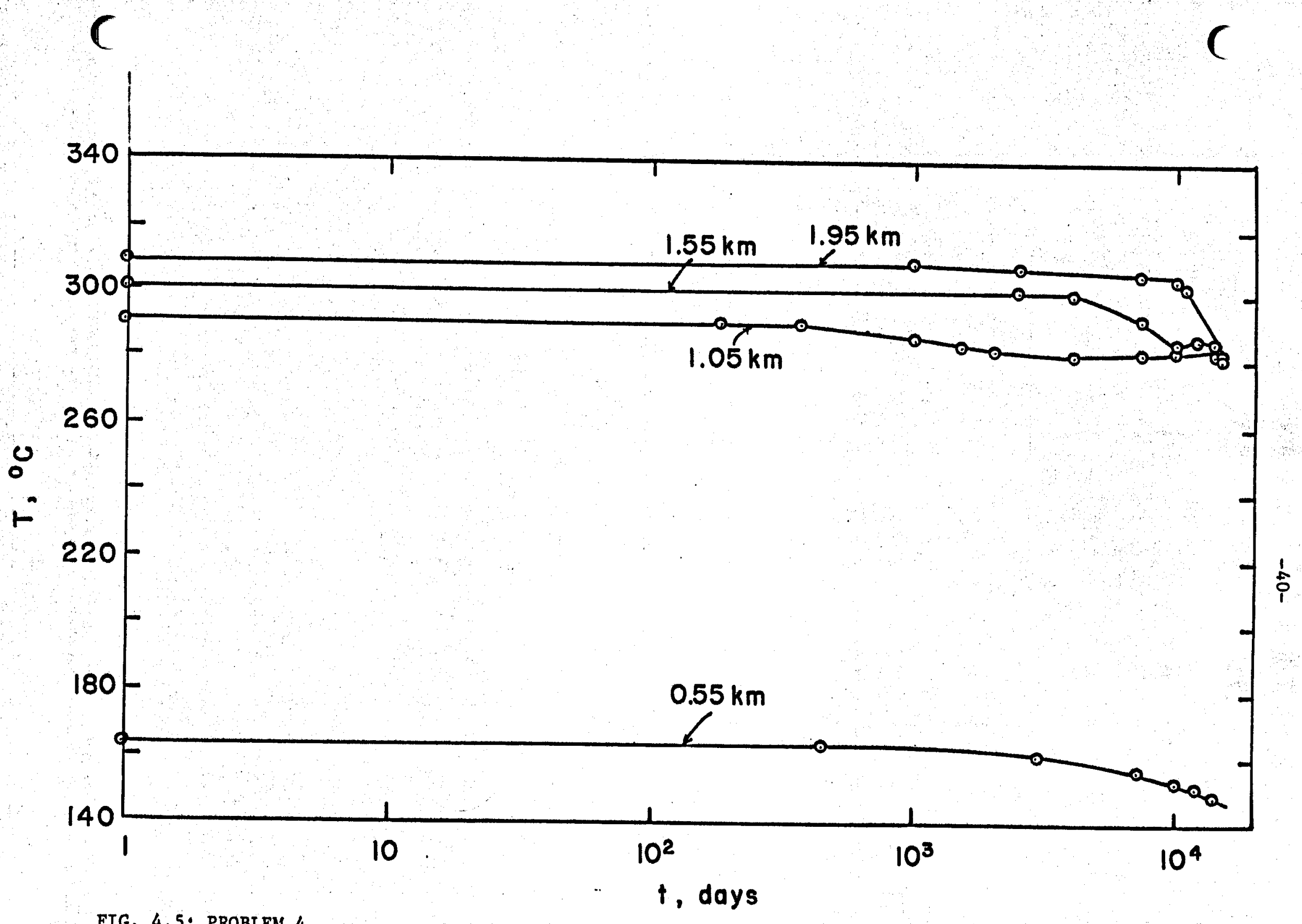

FIG. 4.5: PROBLEM 4 
C

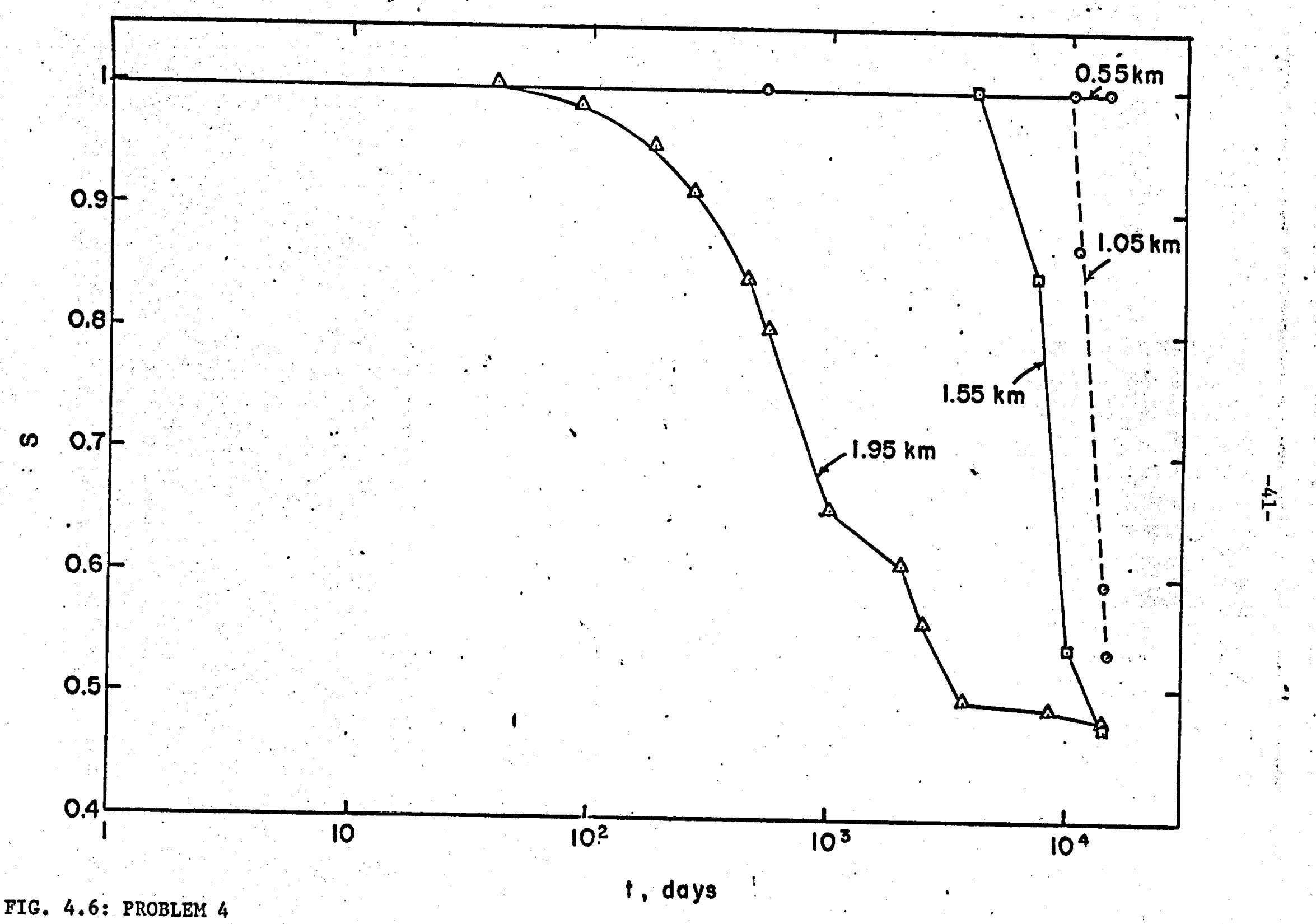


at about 1600 days in Case a and at 365 and 1305 days In Case b, which required time step retirement.

The sequence of time steps taken for Case a was 10 steps of 0.1 days, 20 of $0.2,10$ of $0.5,91$ of 1,709 of 2,150 of $0.5,40$ of $0.1,100$ of $0.02,100$ of 0.1 , and the remainder (to a total of 3650 days) at 0.2 days. The total number of time steps was 2250. In Case b, the sequence was 10 steps of 0.1 days, 20 of $0.2,10$ of $0.5,91$ of 1,132 of 2,10 of 0.1 , 20 of $0.2,20$ of $0.5,20$ of 1,452 of 2,100 of 0.1 , and the remainder at 2 days. The total number of time steps for Case b was 2053.

The required output for Case a is tabulated in Table 5.1. The pressure history in zones $(3,3)$ and $(7,6)$ are graphed in Fig. 5.1. The temperature history in zone $(3,3)$ is graphed in Fig. 5.2. The history of flowing enthalpy in Zone $(3,3)$ is graphed In Fig. 5.3 , and the history of total mass of steam in the system is graphed in Fig. 5.4 .

The required output for Case $b$ is tabulated in Table 5.2. The pressure histories are graphed in Fig. 5.5, and the temperature, flowing enthalpy, and mass of steam histories are graphed in Figs. 5.6, 5.7, and 5.8, respectively.

It should be noted that problem 5 was solved using a $13 \times 8$ grid instead of the $12 \times 8 \mathrm{grid}$ specified. The additional column of nodes was used to achieve the prescribed constant pressure and temperature boundary condition. The specified problem is two-dimensional; however, the program does need to use a thickness in the third dimension. The thickness used was $10 \mathrm{~m}$, although essentially identical results were obtained with a thickness of $1 \mathrm{~m}$ over a shorter test period. 
TABLE 5.1: PROBLEM 5(a)

\begin{tabular}{|c|c|c|c|c|c|c|}
\hline Years & Days & $\begin{array}{c}\text { Pressure } \\
\quad(3,3) \\
(\mathrm{MPa})\end{array}$ & $\begin{array}{c}\text { Pressure } \\
(7,6) \\
(\mathrm{MPa})\end{array}$ & $\begin{array}{c}\text { Temperature } \\
(3,3) \\
\left({ }^{\circ} \mathrm{C}\right)\end{array}$ & $\begin{array}{c}\text { Flowing } \\
\text { Enthalpy } \\
(3,3) \\
(\mathrm{MJ} / \mathrm{kg})\end{array}$ & $\begin{array}{l}\text { Total } \\
\text { Mass of } \\
\text { Steam } \\
\left(10^{4} \mathrm{~kg}\right)\end{array}$ \\
\hline \multirow[t]{2}{*}{0} & .1 & 3.4002 & 3.6517 & 239.9735 & 1.0421 & 0.0 \\
\hline & 181 & 3.2406 & 3.4651 & 237.1724 & 1.0418 & 6.09680 \\
\hline \multirow[t]{2}{*}{1} & 365 & 3.1833 & 3.4381 & 236.1421 & 1.0388 & 10.4610 \\
\hline & 545 & 3.1311 & 3.4123 & 235.1915 & 1.0365 & 13.0624 \\
\hline \multirow[t]{2}{*}{2} & 729 & 3.0849 & 3.3854 & 234.3397 & 1.0306 & 14.0945 \\
\hline & 913 & 3.0576 & 3.3665 & 233.8335 & 1.0178 & 13.7931 \\
\hline \multirow[t]{2}{*}{3} & 1097 & 3.0189 & 3.3494 & 233.1082 & 1.0093 & 12.5288 \\
\hline & 1277 & 3.0461 & 3.3480 & 230.2079 & 0.9955 & 11.0082 \\
\hline 4 & 1461 & 3.0410 & 3.3412 & 227.8894 & 0.9846 & 9.09301 \\
\hline . & 1644 & 3.0582 & 3.3472 & 225.6389 & 0.9739 & 7.17780 \\
\hline \multirow[t]{2}{*}{5} & 1824 & 3.0683 & 3.3519 & 223.3214 & 0.9630 & 5.77520 \\
\hline & 2008 & 3.0705 & 3.3528 & 221.0456 & 0.9525 & 4.50597 \\
\hline \multirow[t]{2}{*}{6} & 2192 & 3.0735 & 3.3586 & 218.7512 & 0.9416 & 3.37035 \\
\hline & 2372 & 3.0825 & 3.3628 & 216.5430 & 0.9313 & 2.59738 \\
\hline \multirow[t]{2}{*}{7} & 2556 & 3.0796 & 3.3634 & 214.2573 & 0.9206 & 1.94288 \\
\hline & 2740 & 3.0837 & 3.3674 & 211.9349 & 0.9098 & 1.38869 \\
\hline \multirow[t]{2}{*}{8} & 2920 & 3.0851 & 3.3698 & 209.7420 & 0.8996 & 1.03283 \\
\hline & 3104 & 3.0843 & 3.3708 & 207.5029 & 0.8893 & 0.753980 \\
\hline \multirow[t]{2}{*}{9} & 3288 & 3.0851 & 3.3726 & 205.2940 & 0.8791 & 0.521211 \\
\hline & 3468 & 3.0861 & 3.3744 & 203.2346 & 0.8696 & 0.415931 \\
\hline 10 & 3648 & 3.0846 & 3.3747 & 201.2343 & 0.8603 & 0.350803 \\
\hline
\end{tabular}




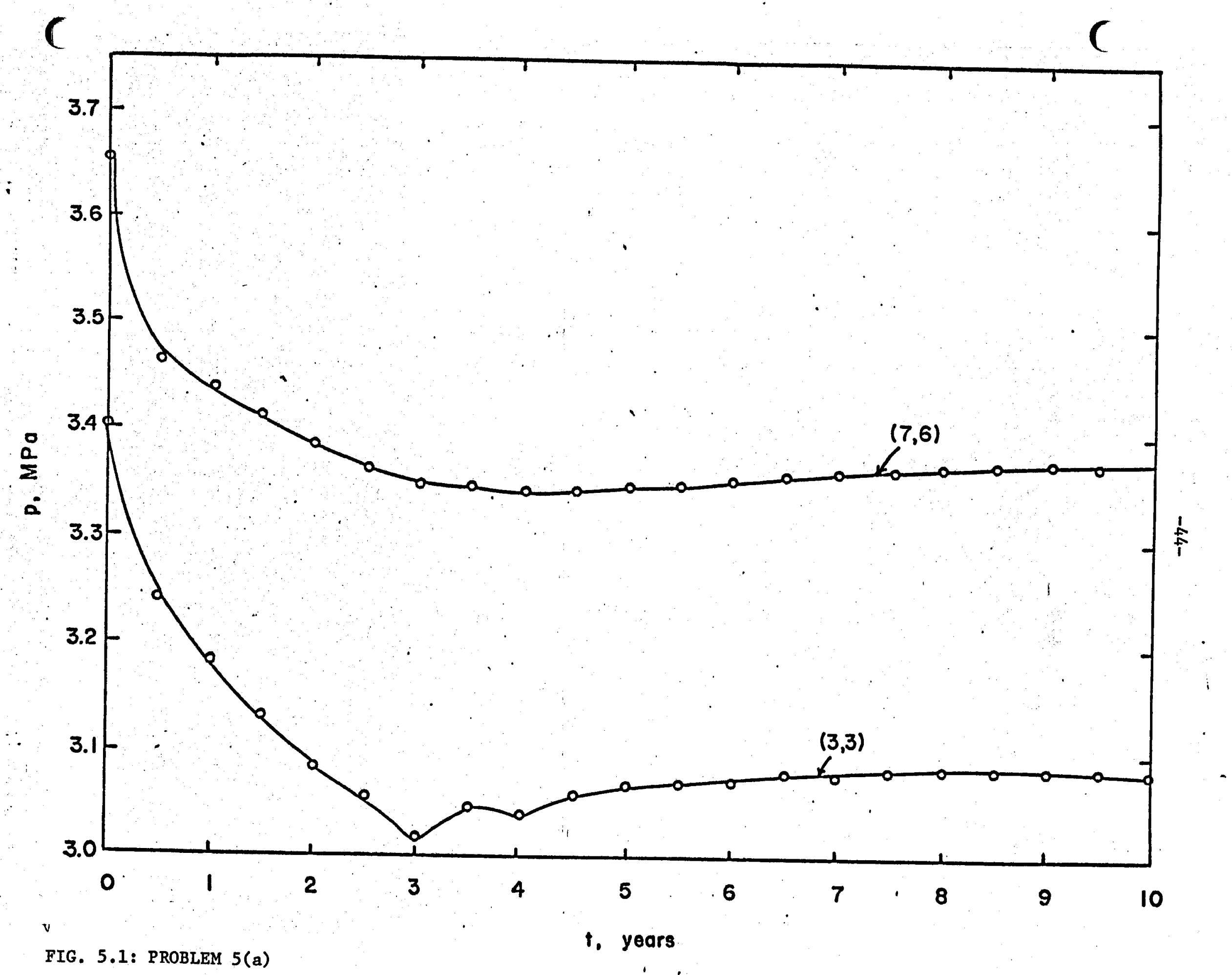




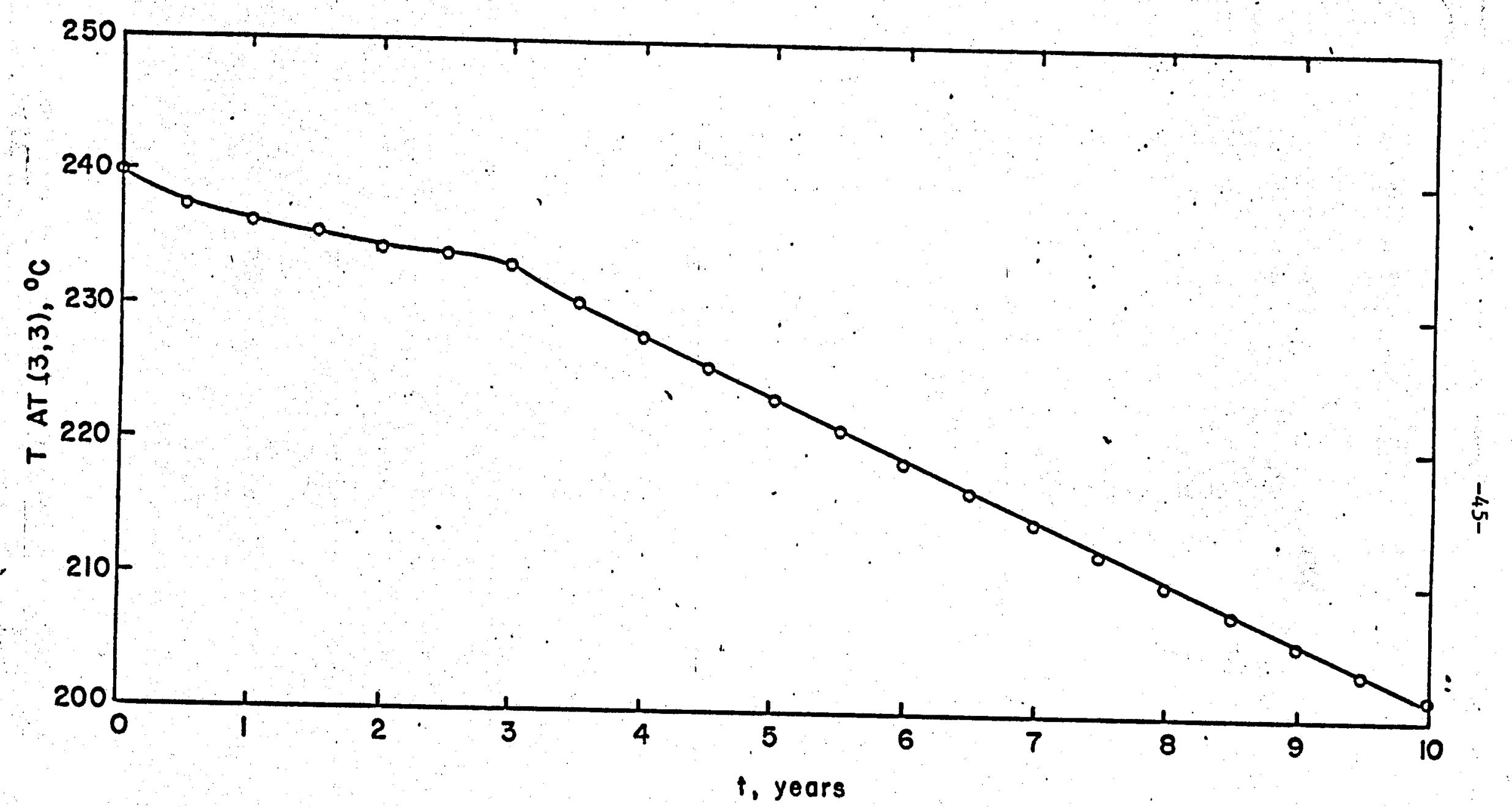

FIG. 5.2: PROBLEM 5(a) 


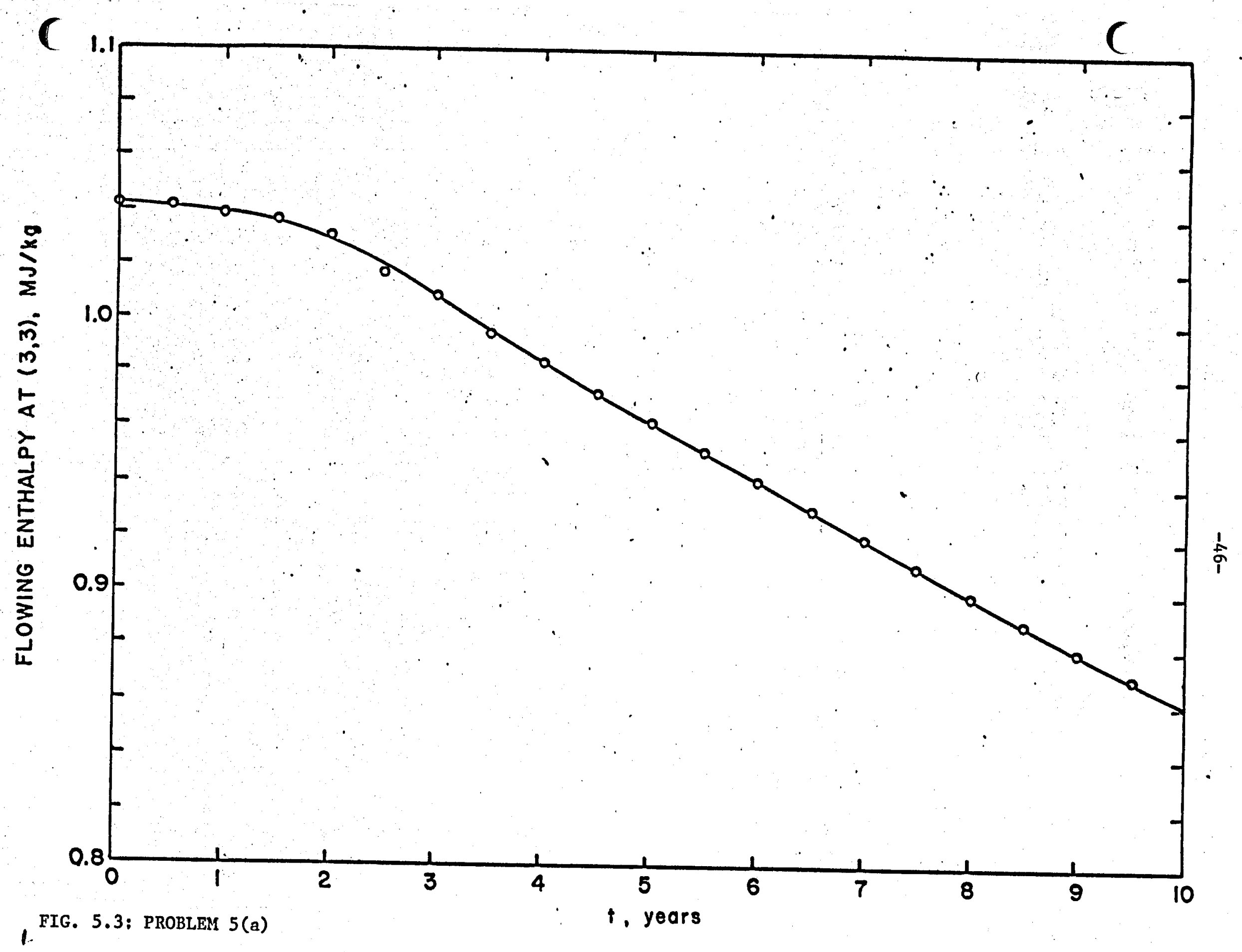




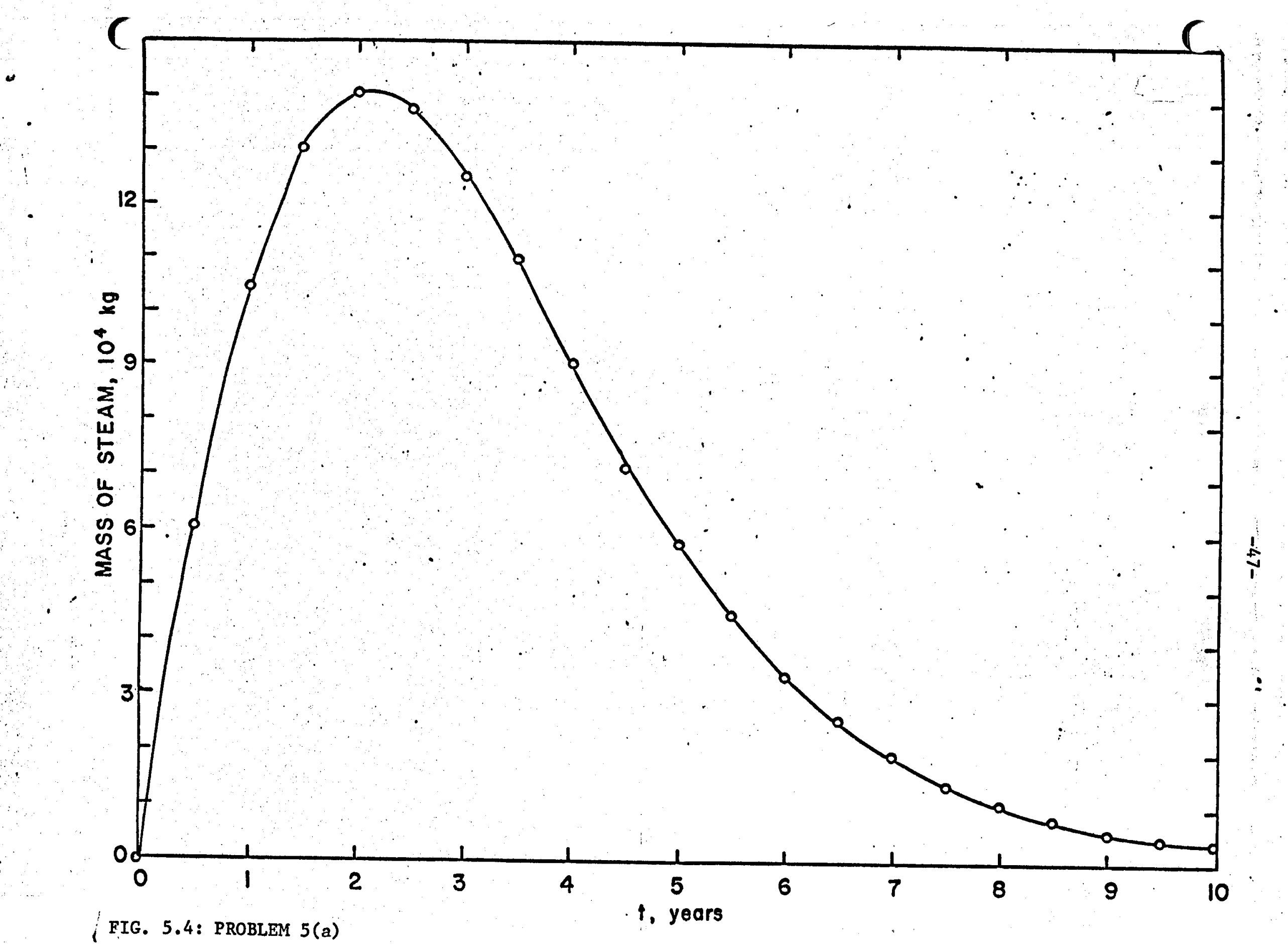


TABLE 5.2: PROBLEM 5(b)

\begin{tabular}{|c|c|c|c|c|c|c|}
\hline Years & $\begin{array}{c}\text { Time } \\
\text { (Days) }\end{array}$ & $\begin{array}{c}\text { Pressure } \\
\qquad(3,3) \\
(\mathrm{MPa})\end{array}$ & $\begin{array}{c}\text { Pressure } \\
(7,6) \\
(\text { MPá) }\end{array}$ & $\begin{array}{c}\text { Temperature } \\
(3,3)^{\circ} \mathrm{C}\end{array}$ & $\begin{array}{c}\text { Flowing } \\
\text { Enthalpy } \\
(3,3) \\
(\mathrm{MJ} / \mathrm{kg})\end{array}$ & $\begin{array}{c}\text { Total Mass } \\
\text { of Steam } \\
\left(10^{4} \mathrm{~kg}\right)\end{array}$ \\
\hline \multirow{4}{*}{1} & .1 & 3.4002 & 3.6517 & 239.9735 & 1.0421 & 0.0 \\
\hline & 185 & 3.2390 & 3.4645 & 237.1278 & 1.0416 & 6.322 \\
\hline & 365 & 3.1833 & 3.4381 & 236.1421 & 1.0388 & 10.461 \\
\hline & 548 & 3.2133 & 3.6027 & 236.6818 & 1.0263 & 9.126 \\
\hline \multirow[t]{2}{*}{2} & 732 & 3.2192 & 3.6236 & 235.3139 & 1.0198 & 7.973 \\
\hline & 912 & 3.2290 & 3.6375 & 233.5647 & 1.0115 & 7.048 \\
\hline \multirow[t]{2}{*}{3} & 1096 & 3.2261 & 3.6426 & 231.7822 & 1.0030 & 6.153 \\
\hline & 1276 & 3.2386 & 3.6511 & 229.8940 & 0.9941 & 5.3999 \\
\hline \multirow[t]{2}{*}{4} & 1462 & 3.2340 & 3.6541 & 227.7 .168 & 0.9838 & 4.869 \\
\hline & 1642 & 3.2345 & 3.6573 & 225.2059 & 0.9720 & 4.357 \\
\hline \multirow[t]{2}{*}{5} & 1826 & 3.2281 & 3.6601 & 222.3555 & 0.9585 & 3.946 . \\
\hline & 2010 & 3.2208 & 3.6609 & 219.1790 & 0.9437 & 3.529 \\
\hline \multirow[t]{2}{*}{6} & 2190 & 3.2143 & 3.6622 & 215.8179 & 0.9279 & 3.083 \\
\hline & 2374 & 3.2156 & 3.6669 & 212.3865 & 0.9120 & 2.726 \\
\hline \multirow[t]{2}{*}{7} & 2554 & 3.2131 & 3.6695 & 208.9580 & 0.8960 & 2.498 \\
\hline & 2738 & 3.2084 & 3.6708 & 205.4445 & 0.8798 & 2.299 \\
\hline \multirow[t]{2}{*}{8} & 2922 & 3.2010 & 3.6707 & 201.9043 & 0.8635 & 2.065 \\
\hline & 3102 & 3.1976 & 3.6723 & 198.5256 & 0.8479 & 1.826 \\
\hline \multirow[t]{2}{*}{9} & 3286 & $3: 1935$ & 3.6738 & 195.1384 & 0.8324 & 1.600 \\
\hline & 3466 & 3.1889 & 3.6747 & 191.8742 & 0.8175 & 1.394 \\
\hline 10 & 3650 & 3.1830 & 3.6748 & 188.5993 & 0.8026 & 1.163 \\
\hline
\end{tabular}




\section{C}

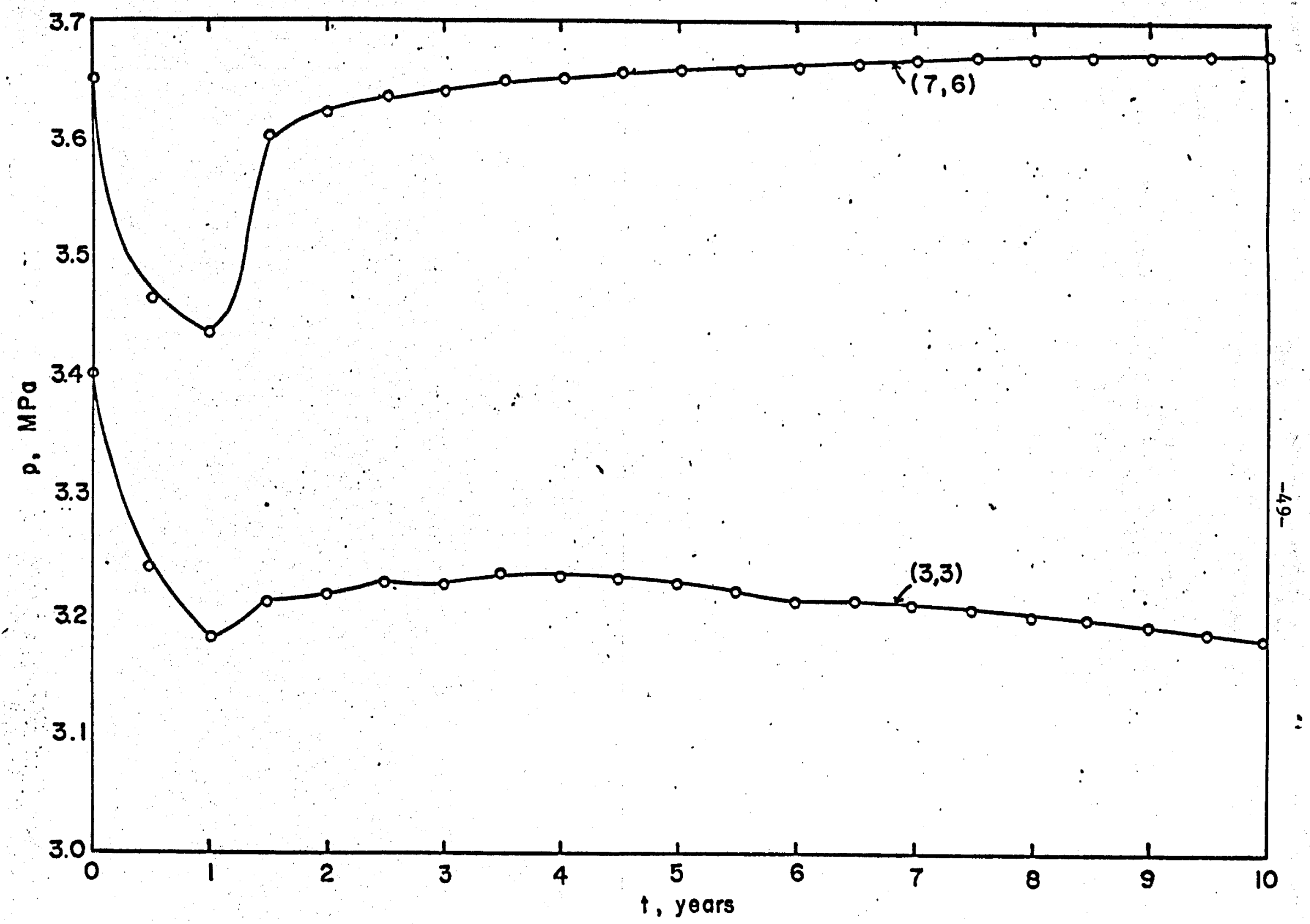

FIG. 5.5: PROBLEM 5(b) 
C

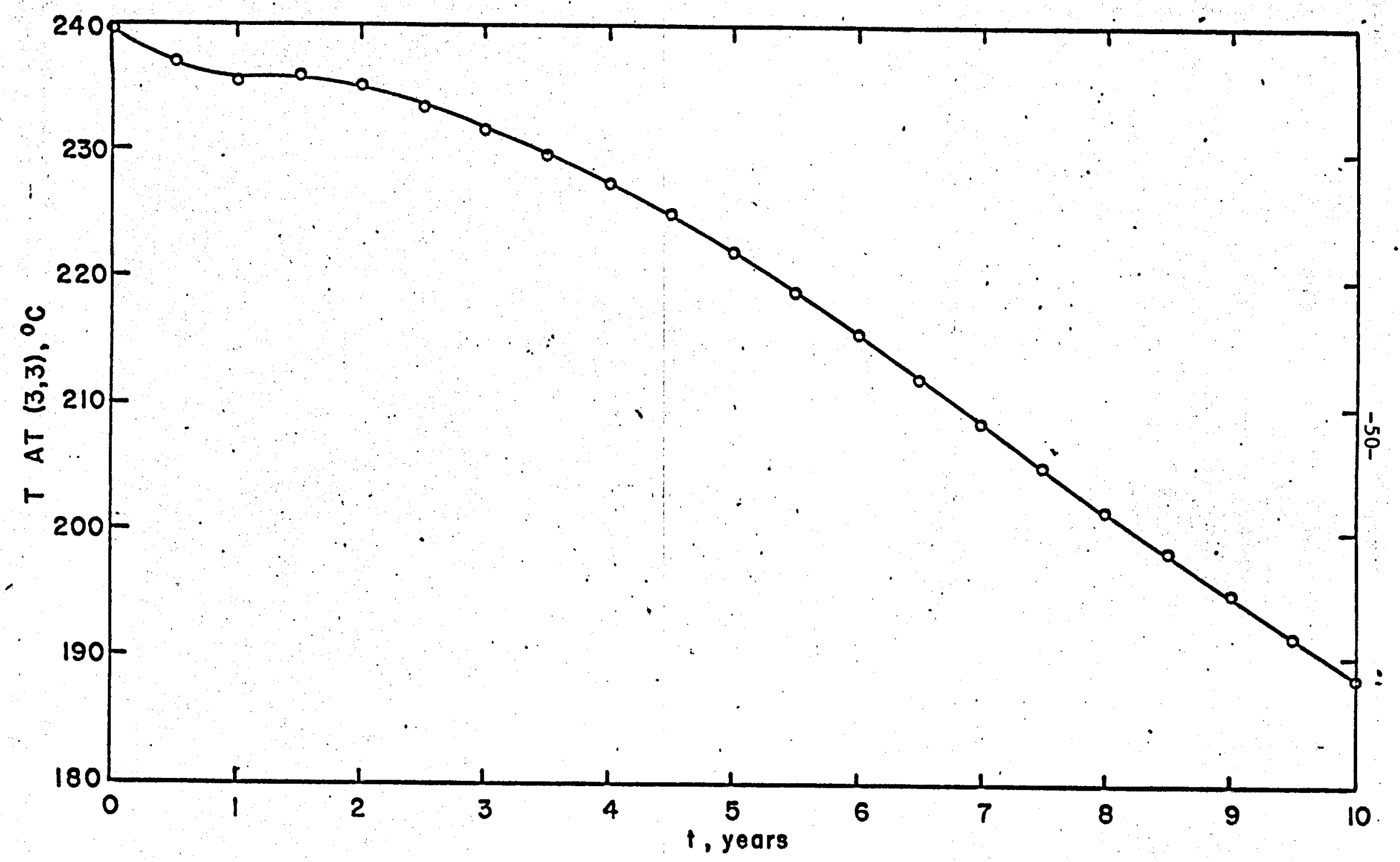

FIG. 5.6: PROBLEM 5(b) 
C

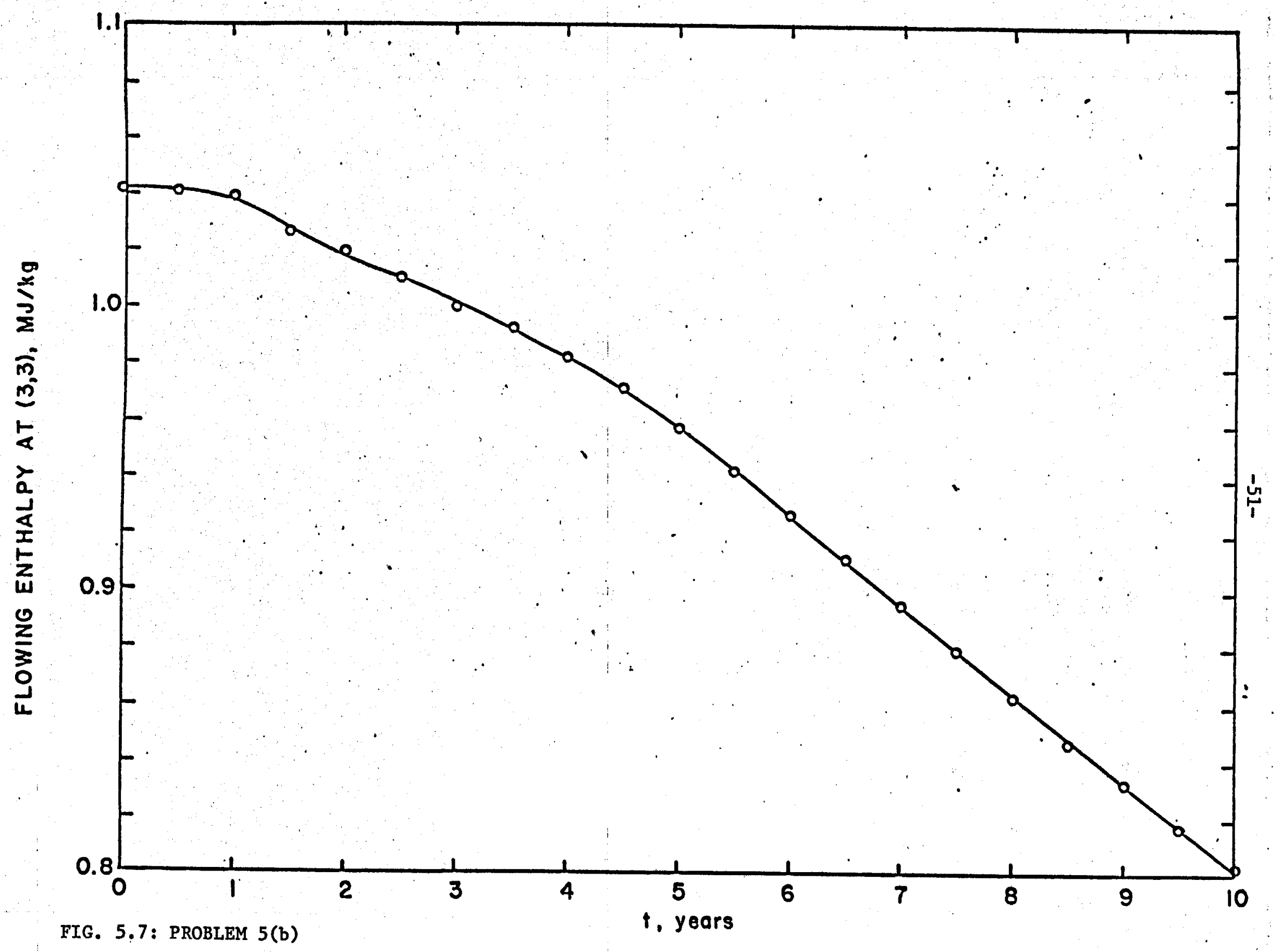




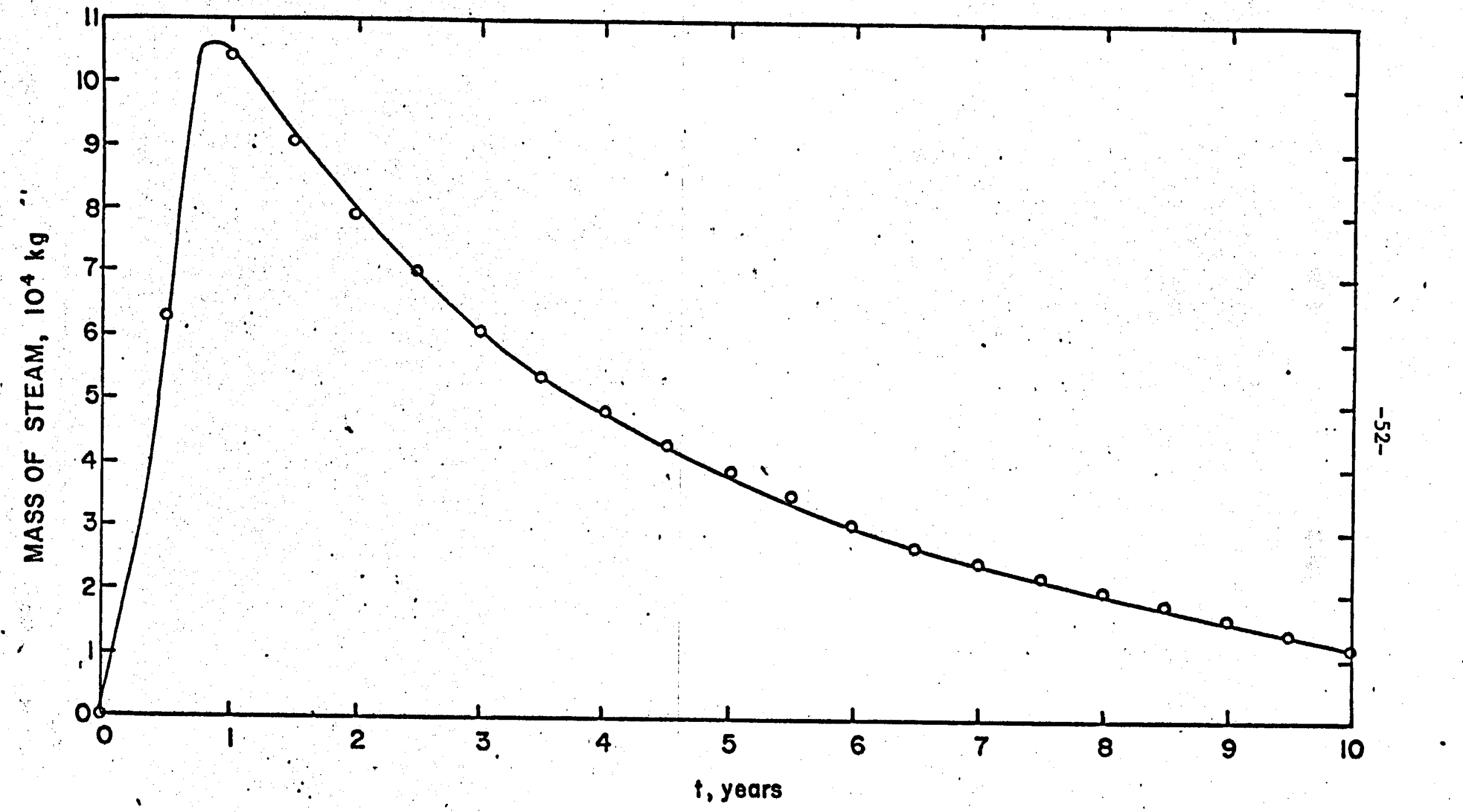

FIG. 5.8: PROBLEM 5(b) 


\section{References}

Faust, C.R., and Mercer, J.W.: "Geothermal Reservoir Simulation 2, Numerical Solution Technlques for Liquid- and Vapor-Dominated Hydrothermal Systems," Water Resources Research (1979), 15, 31-46.

Pritchett, J.W., Garg, S.K., Brownell, D.H., Jr., and Levine, H.B.: "Geohydrological Environmental Effects of Geothermal Power Production Phase 1," Report No. SSS-R-75-2733, Systems, Sclence and Software, La Jolla, California, September 1975.

Pruess, R., Schroeder, R.C., and Zerzan, J.: "Studies of Flow Problems with the Simulator SHAFT 78," Proc., 4th Workshop on Geothermal Reservoir Engineering, Stanford University, Dec. 1978, 308-321:...

Sorey, M.L., Grant, M.A., and Bradford, E.: "Nonlinear Effects in Two-Phase Flow to Wells in Geothermal Reservolrs," Water Resources Research, (June 1980).

Zyvoloski, G.A., O'Sullivan, M.J., and Krol, D.E.: "Finite Difference Techniques for Modeling Geothermal Reservoirs," Num. Anal. Meth. Geomech. (1979), $\underline{3}, 355-366$. 


\section{PROBLEM STATEMENT}

\section{\#1. 1-D Avdonin Solution}

\section{PEYSICAL DESCRTPTION}

This problem involves one-dimensional, radial, steady-state flow, and unsteady heat transport in a single-phase liquid. The purpose is to test heat conduction and convection in the single-phase compressed water region.

\section{PROBLEM SPECIFICATIONS}

Water at $160^{\circ} \mathrm{C}$ is injected into the fringe of a geothermal reservoir of temperature $170^{\circ} \mathrm{C}$. This problem looks at one well and assumes a quasi steady-state flow field is set up very rapidly. The.boundary conditions for flow are: injection rate, $q=10 \mathrm{~kg} / \mathrm{sec}$, specified at the well face, and pressure $=50$ bars at an outer radius of $1000 \mathrm{~m}$. For heat transport, the temperature at the well face Is $160^{\circ} \mathrm{C}$ and at the outer radius is $170^{\circ} \mathrm{C}$. Initial temperature is $170^{\circ} \mathrm{C}$ everywhere in the reservoir, and the initial pressure is 50 bars. Boundary conditions and initial conditions are shown below.

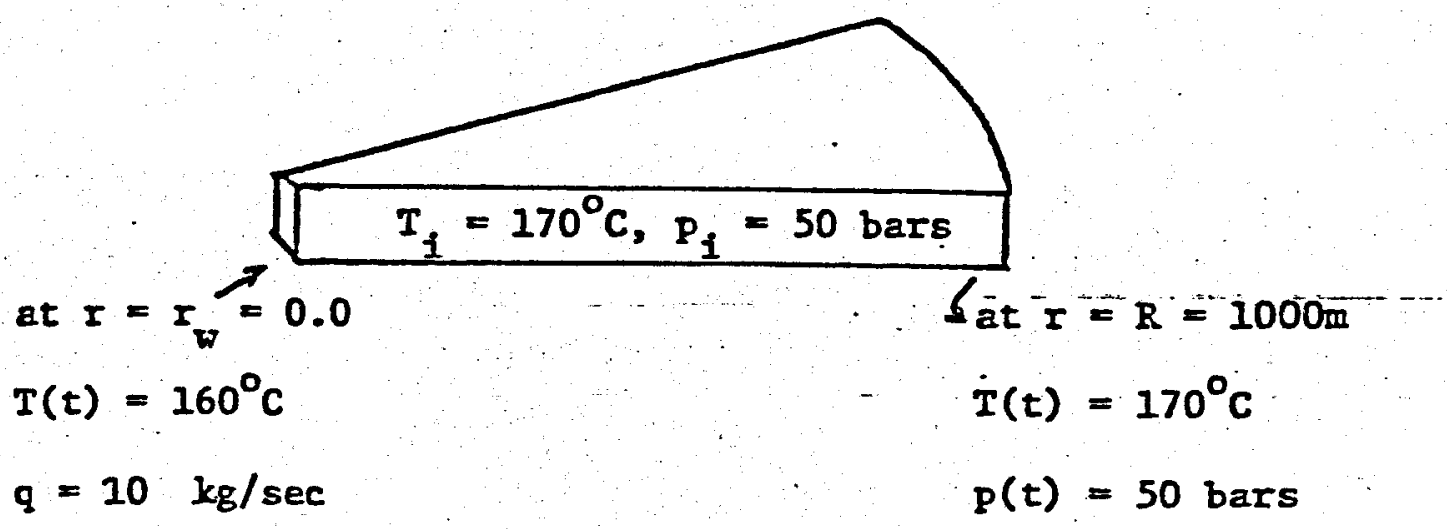




\section{Properties}

permeability $=10^{-12} \mathrm{~m}^{2}$

density rock $=2500 \mathrm{~kg} / \mathrm{m}^{3}$

specific heat of rock $=1.0 \mathrm{~J} / \mathrm{g} .{ }^{\circ} \mathrm{C}$

thermal conductivity $=20 \mathrm{w} / \mathrm{m}^{\circ}{ }^{\circ} \mathrm{C} \ldots \ldots \ldots$

reservolr thickness $=100 \mathrm{~m}$

porosity $=.2$.

\section{Thermal propertles for water}

provided by modeler

specify constants: specific heat, viscosity and density of water ( $165^{\circ} \mathrm{C}, 50$ bars).

Numerical grid and time step data

time steps $=1.67 \times 10^{7} \mathrm{sec}$

grid-spacing $=25 \mathrm{~m}$

\section{OUIPUT SPECIFICATIONS}

1) Temperature versus radial distance at $10^{\circ} \mathrm{sec}$ (60 time steps)

2) Take node at $I=37.5 \mathrm{~m}$ and give solution of temperature versus time.

\section{COMMENTS}

For constant density, viscosity, and heat capacity of water, an analytical solution is available for this problem. For example, this solution is a limiting case of the problem solved by Avdonin, 1964. 


\section{PROBLEM STATERENT}

\section{\#2. 1-D Well Test Analysis}

\section{PEYSICAI DESCRTPTION}

This problem involves a set of three constant discharge, transient well test cases. Each case has 1-D radial flow to a Iine sink (zero radius well) in a homogeneous porous media. In Case a the fluid is single-phase IIquid; in Case b the fluid is a two-phase mixture with both water and steam mobile; and in Case $c$ the fluid changes from compressed liguid to a two-phase mixture as flash front propogates away from the well. For each case, elther an exact analytical solution (Theis solution) or an accurate semi-analytical solution is available for compe-ison with numerical solutions. Solutions will consist of pressure, sefuration, and flowing enthalpy changes as functions of $t / r^{2}$ (time/dis ance squared).

\section{PROBLEM SPECIE=EATIONS}

The foll ing initial and boundary conditions and parameter values are to be use=

Specification

Initial press $=$ (bars)

Initial liquie seturation

Initial tempe = $=\left({ }^{\circ} \mathrm{C}\right)$

Porosity

Permeability $\left(-5^{-12} \mathrm{~m}^{2}\right)$

Thickness ( $\mathrm{g}$ )

Discharge ( $\mathrm{kg} \equiv$ )

Rock heat cep $=-y\left(\mathrm{~kJ} / \mathrm{m}^{30} \mathrm{C}\right)$

Rock compress $=-7$ ity

Relative permajity functions 2/

Rock thermal
Case a

90
1
260

100

14.0

2650

0

1-ph

0
Case b

30 .65

$233.81 /$

.15

.24

100

16.7

2000

0

Corey

0
Case c

90

1 300 100 14.0 2650

0 Corey 0

I/ Saturatic Iemperature at 30 bars

2f $k_{I w}=\left[S=k_{r S}=\left[\left(1-S^{*}\right)^{2}\right] \cdot\left[1-\left(S^{*}\right)^{2}\right], s^{*}=[(S-.3) /(.65)]\right.$, 
NUMERICAL SOLUTIONS

Analytical results for each case indicate that solutions for pressure, saturation, and flowing enthalpy are functions of $t / r^{2}$. To minimize computational requirements while avoiding the significant spatial discretization errors, the following nodal arrangement should be used for each case.

$$
r_{n}=0.5(\sqrt{2})^{n-1} \quad n=1,26
$$

Total simulation time in each case should be 1 day. For the grid specification given above, an initial time step near $10^{-4}$ or $10^{-5}$ days is suggested for accurate solutions at early times.

ONE NODE TWO-PHASE PROBLEM

To facilitate evaluation of numerical solutions for two-phase flow, an additional problem under Case b conditions should be rum. It involves 1 grid block with volume $=314 \mathrm{~m}^{3}$ and constant discharge of $16.7 \mathrm{~kg} / \mathrm{s}$ for .01 days. A constant time step of $10^{-4}$ days should be used, and the enthalpy of the discharge fluid should be weighted according to the mobility of each fluid phase (as in Cases $b$ and $c$ ). OUTPUT SPECIFICATIONS

Results for each case, except for the one-node problem, should consist of plots of pressure in bars, IIquid saturation (Cases b and c), and flowing enthalpy in $\mathrm{kJ} / \mathrm{kg}$ (Cases $\mathrm{b}$ and c) as functions of $\mathrm{log}$ $\left(t / \mathrm{r}^{2}\right)$ in days $/ \mathrm{m}^{2}$ for nodal points at $0.5 \mathrm{~m}, 0.707 \mathrm{~m}$ and $1.0 \mathrm{~m}$ from the well. The corresponding data in tabular form should also be provided. Data covering 5 log cycles for Cases a and $k$ and 4 log cycles 
for Case b should be Included in the plots and tabulations. Spectfication of the time step variation utilized should also be provided. Results for the one-node problem should consist of plots of pressure, Iiquid saturation, and discharge enthalpy versus time, along with the corresponding data tabulations. 
PROBLEM STATEMIENT

\#3. 2-D Flow to a Well in Fracture/Block Media

\section{PEYSICAL DESCRIPTION}

This problem represents a simplification of the general problem of well testing in fractured geothermal reservoirs. As shown in the following sketch, a well producing at constant discharge is open to a horizontal fracture of Infinite lateral extent. Vertical flow in the block and radial flow in the fracture, each obeying Darcy's law,

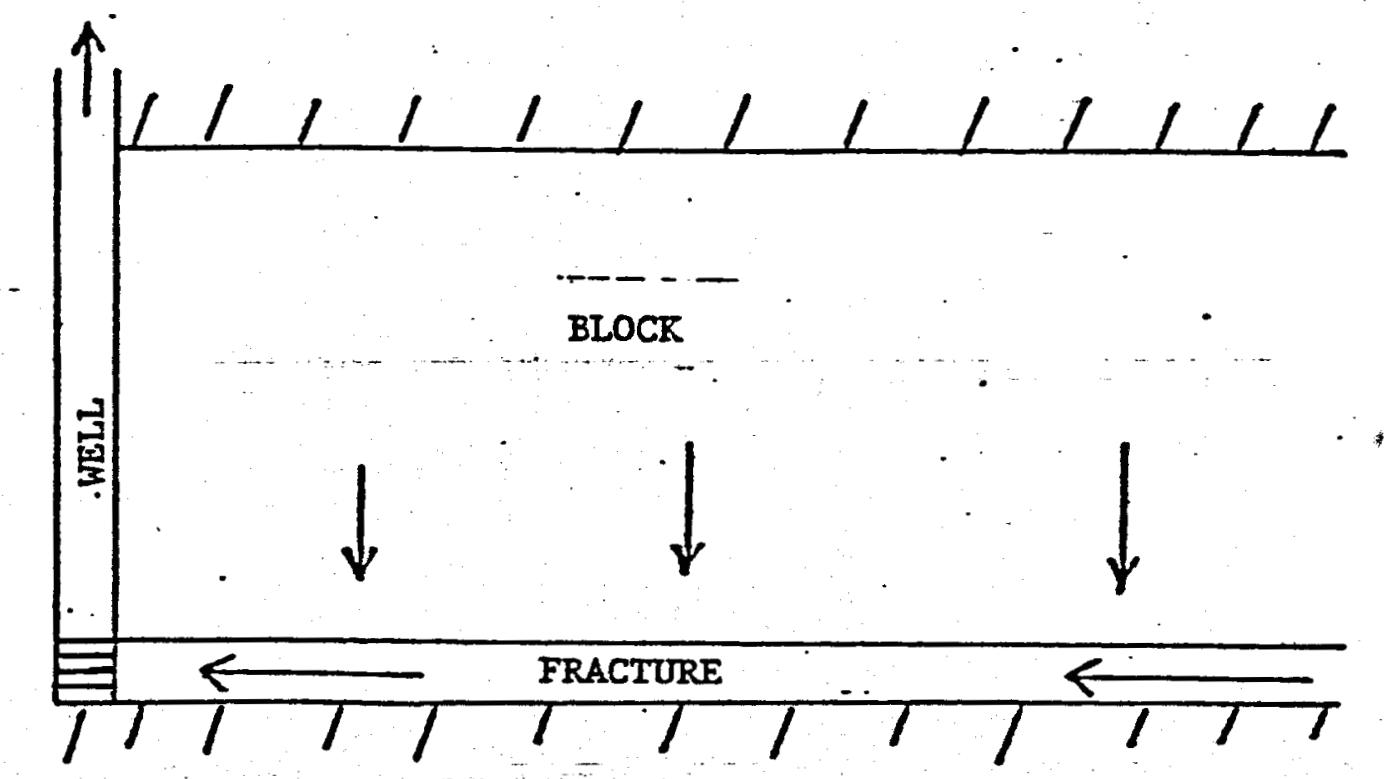

Is to be simulated. The upper boundary of the block and the lower Joundary of the fracture are impermeable, and the well has a finite =adius with well-bore storage. 
PROBLEM SPECIFICATIONS

For application to vapor-dominated reservoirs, steam flow in the block and fracture will be simulated. Parameter specifications for two cases are listed below:

Specification

Initial pressure (bars)

Initial Iiquid saturation $I /$ (in block)

Initial temperature ( $\left.{ }^{\circ} \mathrm{C}\right) 2 \frac{7}{7}$

Porosity in fracture

Porosity in block

Permeakfict in fracture $\left(10^{+12} \mathrm{~m}^{2}\right)$

Permeability in block $\left(10^{-\frac{1}{2} \mathrm{~m}^{2}}\right) 3 /$

Thickness of fracture (m)

Thickness of block (m)

Well discharge $(\mathrm{kg} / \mathrm{s})$

Well radius (m)

Rock heat capacity $\left(\mathrm{kJ} / \mathrm{m}^{30} \mathrm{C}\right)$

Rock compressibility

Rock thermal conductivity
Case a

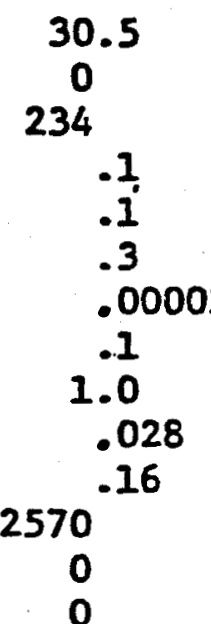

Cese b

$$
30.5
$$

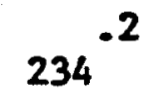

2

.1

.1

.3

.00003

.1

1.0

.028

.16

0

0

If Intial liquid saturation is zero in the fracture in both cases

2/ Saturation temperature at 30.5 bars

3/ Eorizontal permeability in block is zero in both cases

In Case a, liquid saturation is zero everywhere (no boiling). In

Case $b$, immobile liquid boils in the blocks but not in the fracture.

Relative permeability to steam is 1.0 in both cases.

NUMERICAL SOLUTION

A computational grid consisting of 1 weil block, 10 logarithmically-spaced nodes in the fracture, and 100 nodes of equal vertical thickness in the block should be used. For those codes using finite difference techniques, either block-centered or face-centered nodal 
patterns could be used provided that nodal positions were approximately the same as those shown below. The porosity and permeability in the well block should be set to 1.0 and $30 \times 10^{-12} \mathrm{~m}^{2}$ (or larger), respec- . tively.

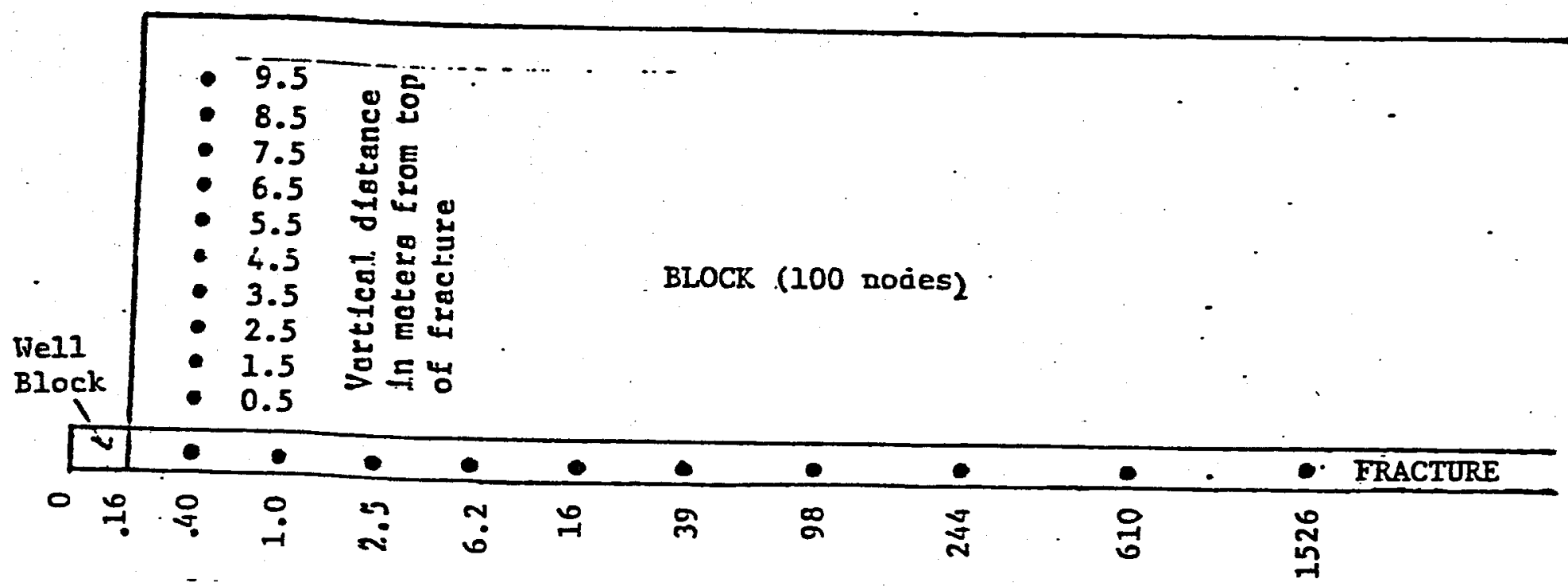

IE: $=\geq 1$ distance in meters from center of well.

Total $5=$ ation time should be $10^{4} \mathrm{~s}$ or more, and to define the pressure hiss: at the well face an initial time step of $1 \mathrm{~s}$ should be used. Mi = simulation time of $10^{4} \mathrm{~s}$ would be reached in about 130 time stes = = a time step multiplication factor of 1.05 were used.

\section{OUIPUT SPECI $=$-TIONS}

Results $=$ Cases $a$ and $b$ should consist of plots of pressure as a function of $=\rightarrow$ (time), along with the corresponding data in tabular form. Fe $=c h$ case, plot pressure at the well face, and pressure at a point low $2.5 \mathrm{~m}$ from the center line of the well and $2.5 \mathrm{~m}$ above the top $=$ the fracture. Include a tabulation of liquid saturation versus $=$ for this same point in the block under Case b conditions. The =ired data for each case should cover at least 4 log cycles in tim 


\section{PROBLEM STATEMENT}

\#4. Expanding 2 Phase System with Drainage

PEYSICAL DESCRIPTION

This problem involves $1-D$ vertical flow under both single and two phase conditions. An initially hydrostatic colum of liquid is disturbed by mass withdrawal at the bottom. Boiling occurs in portions of the column, and inflow of cold water is induced at the top.

PROBLEM SPECIFICATIONS

1-D Cartesian (Vertical) Geometry

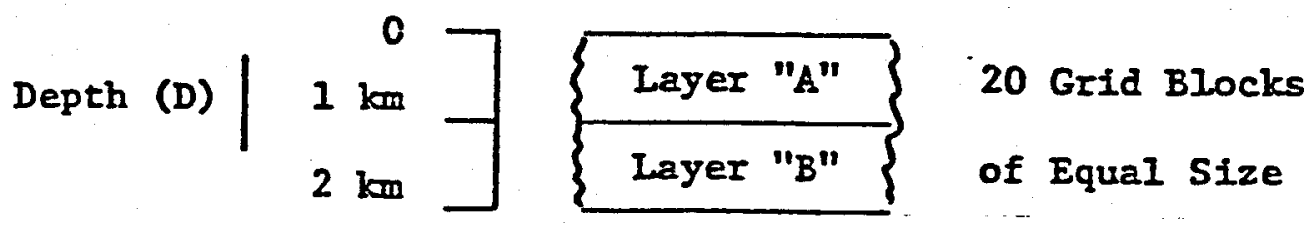

$$
8=9.8 \mathrm{~m} / \mathrm{s}
$$

Rock Properties

\begin{tabular}{|c|c|c|}
\hline & $\begin{array}{l}\text { Layer "A" } \\
(0 \leq D \leq 1 \mathrm{~km})\end{array}$ & $\begin{array}{l}\text { Layer "B" } \\
(1 \text { km<D } \leq 2 \mathrm{~km})\end{array}$ \\
\hline Grain Density $\left(\mathrm{g} / \mathrm{cm}^{3}\right)$ & 2.5 & 2.5 \\
\hline Porosity & 0.15 & 0.25 \\
\hline Permeability $\left(\mathrm{m}^{2}\right)$ & $5 \times 10^{-15}$ & $100 \times 10^{-15}$ \\
\hline Heat Capacity $\left(\mathrm{J} / \mathrm{g}-{ }^{\circ} \mathrm{C}\right)$ & 1 & $I$ \\
\hline $\begin{array}{l}\text { Grain Thermal Conductivity } \\
\left(\mathrm{W} / \mathrm{m}-{ }^{\circ} \mathrm{C}\right)\end{array}$ & 1 & 1 \\
\hline
\end{tabular}

Relative Permeability Functions: Corey (as specified in Problem \#2) 


\section{Boundary Conditions}

At $D=0 \quad$ (Surface), $P=1.013 \mathrm{Bar}(\sim 1 \mathrm{~atm}), \quad T=10^{\circ} \mathrm{C}$ At $D=2 \mathrm{~km}$, see below.

\section{Initial Conditions}

$$
\begin{aligned}
T(D) & =[10+280(\mathrm{D} / 1 \mathrm{~km})]^{\circ} \mathrm{C} & & \underline{0 \leq D} \leq 1 \mathrm{~km} \\
& =[270+20 \mathrm{(D} / 1 \mathrm{~km})]^{\circ} \mathrm{C} & & 1 \mathrm{~km} \leq \mathrm{D} \leq 2 \mathrm{~km}
\end{aligned}
$$

$P(D)=1.013 \mathrm{Bar}+\int_{0}^{D} \mathrm{pg} \mathrm{dD} ;$ hydrostatic.

\section{Production Strategy}

From $t=0$, to 40 years extract fluid from the bottom of the system $(D=2 \mathrm{~km})$ at a rate of $100 \mathrm{~kg} / \mathrm{s}-\mathrm{km}^{2}$.

\section{OUTPUT SPECIFICATIONS}

Plot and Tabulate:- Discharge enthalpy history of the produced fluid. Recharge rate and cumulative recharge at the surface $(D=0)$. $P(t), T(t)$ and $S(t)$ at $D=0.5,1.0,1.5$ and $2.0 \mathrm{~km}$. 


\section{PROBLEM STATEMENT}

\#5. Flow in a 2-D Areal Reservoir

PEYSICAI DESCRIPTION

This problem involves multiphase flow in a 2-D borlzontal reservoir. Mass is produced at one point in the reservoir, and recharge. is induced over one of the lateral boundaries.

\section{PROBLEM SPECIFICATIONS}

\section{2-D Areal Geometry}

Region is horizontal (gravity neglected; $\varepsilon_{x}=g_{y}=0$ ) and of uniform tbickness; extends over $0 \leq x \leq 300$ meters, $0 \leq Y \leq 200$ meters Finite - difference zoning as indicated: $12 \times 8$ grid (96 zones total) ô uniform size $\Delta x=\Delta y=25$ meters. 


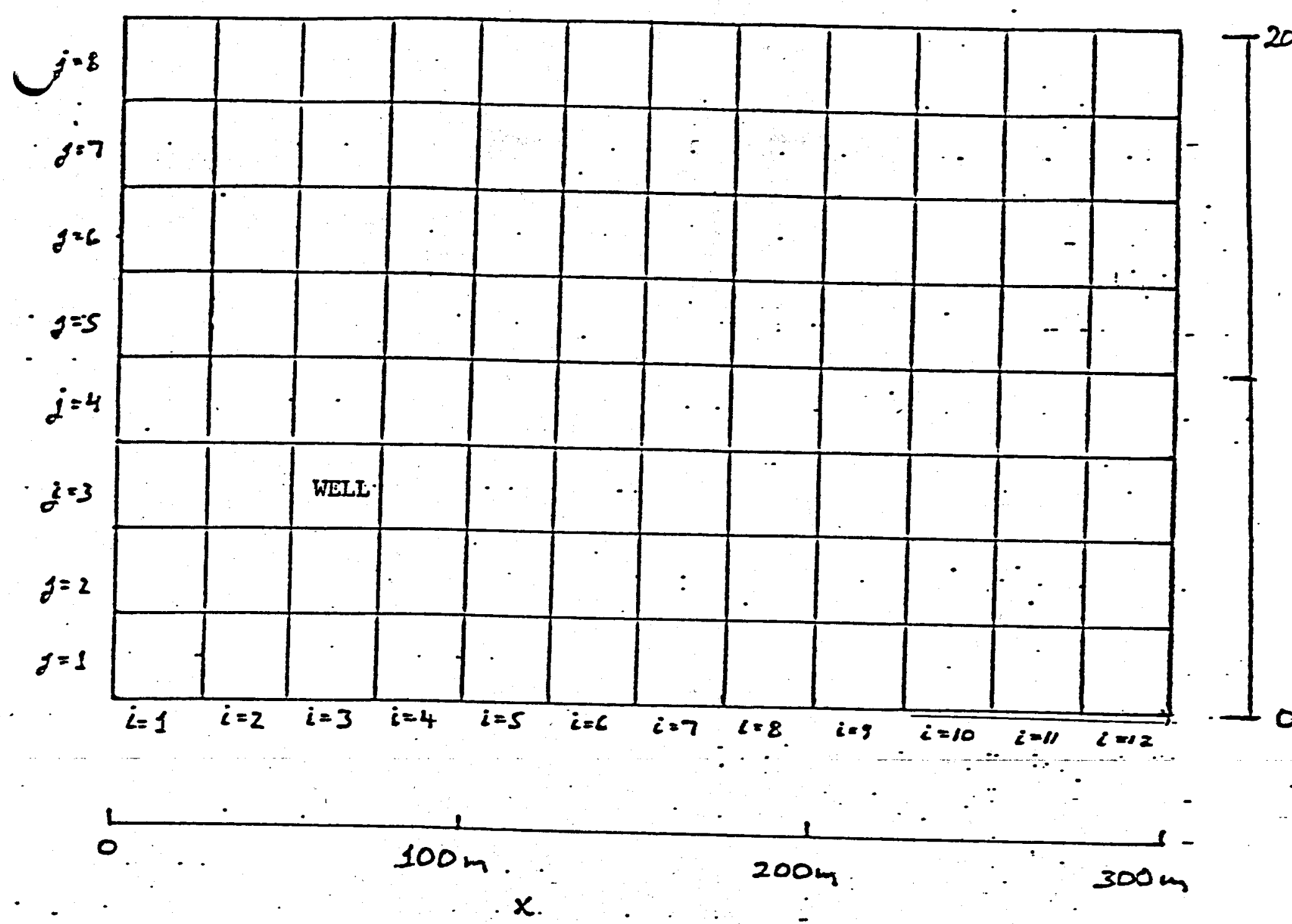

Rock Properties (Uniform over Grid):

Rock Grain Density $=2.5 \mathrm{~g} / \mathrm{cm}^{3}$

Porosity $=0.35$

Permeability $\left(k_{x}=k_{y}\right)=2.5 \times 10^{-24} \mathrm{~m}^{2}$

Heat Capacity of Rock Grain $=1 \mathrm{~J} / \mathrm{g}-{ }^{\circ} \mathrm{C}$

Rock Thermal Conductivity $=1 \mathrm{w} / \mathrm{m} .{ }^{\circ} \mathrm{C}$

Relative Permeabilities - Corey Equations as in Problem \#2 with

$$
s_{1 r}=0.3, s_{g x}=0.1
$$


Boundary Conditions: (See Figure Below)

Impose no convection, no conduction (impermeable, insulated) along:

$y=200 m, 0 \leq x \leq 300 m$

Maintain inttial P, T along $x=300 m, 0 \leq y \leq 200 m$

$\left(\mathrm{P} \times 36\right.$ bars, $\left.\mathrm{T}=160^{\circ} \mathrm{C}\right)$; see below

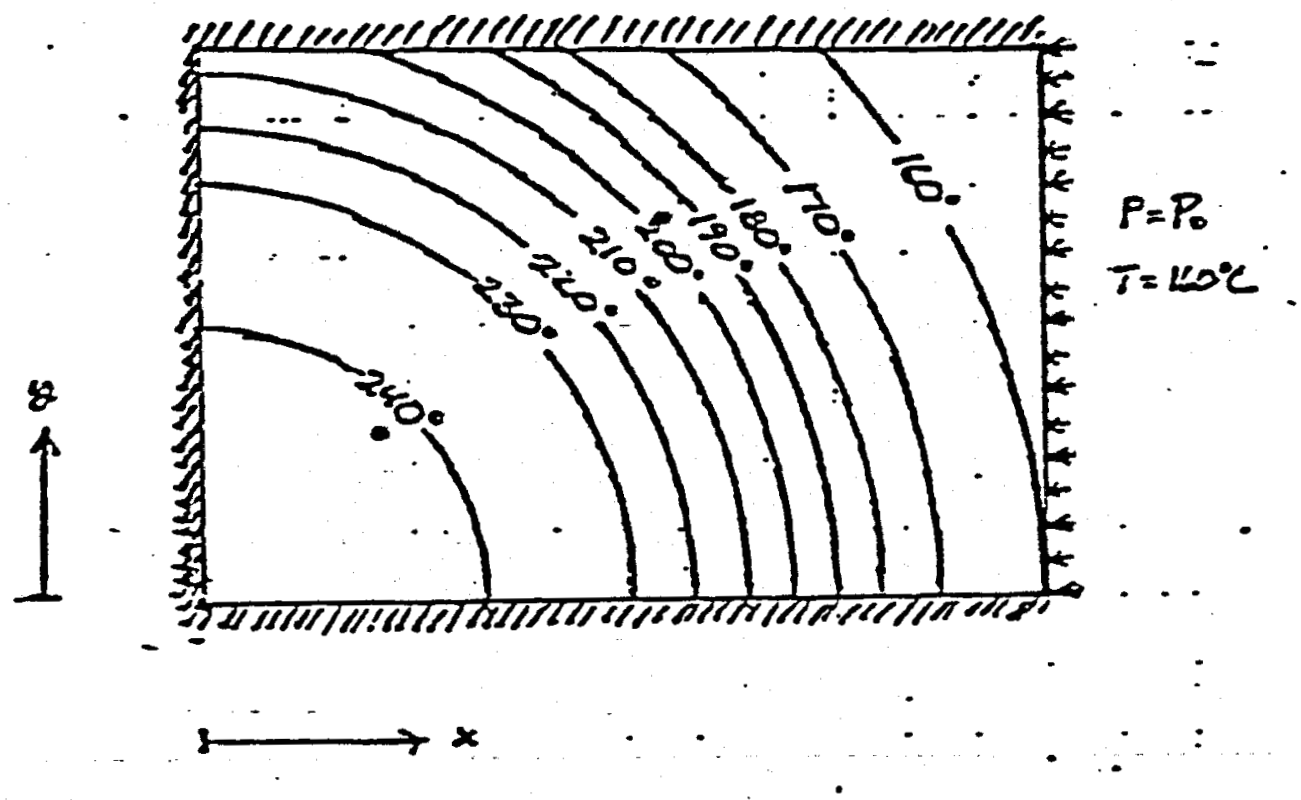

\section{Initial CoI = zions:}

Pressure i $=-i=17$ y uniform, and equal to saturation pressure at $240^{\circ} \mathrm{C}$,

plus $2.5 \mathrm{bas}=$

$$
\begin{aligned}
I(t & =D, 0 \leq x \leq 300 \mathrm{~m}, 0 \leq y \leq 200 \mathrm{~m})= \\
& ={ }_{\operatorname{set}}\left(240^{\circ} \mathrm{C}\right)+2.5 \text { bars }
\end{aligned}
$$

Initial telectures for each zone are provided on the table on the next pase. Zney are given approximately by:

$$
\begin{aligned}
& I\left(t=240^{\circ} \mathrm{C} \text { for } I \leq 100 \mathrm{~m}\right. \\
& =\left[240-160\left(\frac{r-100 m}{200 m}\right)^{2}+80\left(\frac{r-100 m}{200 m}\right)^{4}\right]^{0} \mathrm{C} \\
& \text { fo } \bar{x} \quad 100 \mathrm{~m}<\mathrm{r}<300 \mathrm{~m} \\
& =160^{\circ} \mathrm{C} \text { for } \mathrm{r} \leq 300 \mathrm{~m} \\
& \dot{\text { inere }} \quad \mathrm{I} \equiv \sqrt{x^{2}+y^{2}}
\end{aligned}
$$


Initial Temperatures $\left({ }^{\circ} \mathrm{C}\right) \mathrm{T}_{i j}(t=0)$ :

\begin{tabular}{|c|c|c|c|c|c|c|c|c|c|c|c|}
\hline $2 \dot{12.07}$ & 210.18 & 206.41 & 200.81 & 193.59 & 185.18 & 176.31 & 168.09 & 162.03 & 160.00 & 160.00 & 160.00 \\
\hline 224.92 & 223.16 & 219.54 & 213.95 & 206.41 & 197.16 & 186.79 & 176.31 & 167.13 & 161.12 & 160.00 & 160.00 \\
\hline 234.31 & 232.93 & 229.92 & 224.92 & 217.70 & 208.29 & 197.16 & 185.18 & 173.71 & 164.58 & 160.11 & 160.00 \\
\hline 239.31 & 238.62 & 236.74 & 232.93 & 226.64 & 217.70 & 206.41 & 193.59 & 180.56 & 169.11 & 161.54 & 160.00 \\
\hline 240.00 & 240.00 & 239.77 & $237 . .6$ & 232.93 & 224.92 & 213.95 & 200.81 & 186.79 & 173.71 & 163.85 & 160.00 \\
\hline 240.00 & 240.00 & $\begin{array}{c}\text { WELL } \\
240.00\end{array}$ & 239.77 & 236.74 & 229.92 & 219.54 & 206.41 & 191.85 & 177.68 & 166.22 & 160.26 \\
\hline 240.00 & 240.00 & 240.00 & 240.00 & 238.62 & 232.93 & 223.16 & 210.18 & 195.36 & 180.56 & 168.09 & 160.77 \\
\hline 240.00 & 240.00 & 240.00 & 240.00 & 239.31 & 234.31 & 224.92 & 212.07 & 197.16 & 182.06 & 169.11 & 161.12 \\
\hline$i=1$ & $i=2$ & $i=3$ & $i=4$ & $i=5$ & $i=6$ & $i=7$ & $i=8$ & $i=9$ & $i=10$ & $i=11$ & $i=12$ \\
\hline
\end{tabular}

Production Strategy for Case A

A fully-penetrating production well is located at $x-62.5 \mathrm{~m}$, $y-62.5 m$ (at the center of zone $i=3, j=3$ ). Starting at $t=0$, it produces fluid at the constant rate of $0.05 \mathrm{kilograms} / \mathrm{sec}-m e t e r$ of thickness. The well radius is $15 \mathrm{~cm}$ and no skin effect is present.

Production Strategy for Case B

A production well is present, identical to Case A. In addition, an injection well is located at $x=162.5 \mathrm{~m}, y=137.5 \mathrm{~m}$, at the center of zone $i=7, j=6$. The well is fully penetrating, has no skin effect, 
and is of radius $15 \mathrm{~cm}$. The injection well is inoperative until

$t=1$ year $\left(3.1536 \times 10^{7} \mathrm{sec}\right)$. Thereafter, it begins injecting water at $\mathrm{T}-80^{\circ} \mathrm{C}$ at a rate of $0.03 \mathrm{kilograms} / \mathrm{sec}$-meter of thickness.

\section{OUIPUT SPECIFICATIONS}

In both cases, the time domain of interest is

$0 \leq t \leq 10$ years $\left(3.1536 \times 10^{\circ} \mathrm{sec}\right)$

For cases $A \& B, p l o t$ and tabulate:

(1) Pressure histary in zones $i=3, j=3$ and $i=7, j=6$.

(2) Temperature history in zones $1=3, j=3$.

(3) Eistory of discharge (flowing) enthalpy in zone $i=3, j=3$.

(4) Fariation with time of total mass of steam in the system Đer meter of thickness.

Optional (三or those with subgrid well model):

(5) Dat is the sandface pressure history for the production

- 77 in cases A\& B?

(6) Whet is the sandface pressure history for the injection 77 in Case B?

(7) that is the sandface steam saturation history at the proEction weli in cases $A \& B$ ? 